\title{
Brain-gut-microbe communication in health and disease
}

\author{
Sue Grenham 1, Gerard Clarke ${ }^{1,2}$, John F. Cryan ${ }^{1,3}$ and Timothy G. Dinan ${ }^{1,2}$ * \\ ' Laboratory of NeuroGastroenterology, Alimentary Pharmabiotic Centre, University College Cork, Cork, Ireland \\ 2 Department of Psychiatry, University College Cork, Cork, Ireland \\ ${ }^{3}$ Department of Anatomy, University College Cork, Cork, Ireland
}

Edited by:

Stephen J. Pandol, University of California at Los Angeles, USA

Reviewed by:

Eileen F. Grady, University of

California at San Francisco, USA

Govind K. Makharia, All India Institute

of Medical Sciences, India

*Correspondence:

Timothy G. Dinan, Department of

Psychiatry, GF Unit, Cork University

Hospital, Wilton, Cork, Ireland.

e-mail:t.dinan@ucc.ie
Bidirectional signalling between the gastrointestinal tract and the brain is regulated at neural, hormonal, and immunological levels. This construct is known as the brain-gut axis and is vital for maintaining homeostasis. Bacterial colonization of the intestine plays a major role in the post-natal development and maturation of the immune and endocrine systems. These processes are key factors underpinning central nervous system (CNS) signaling. Recent research advances have seen a tremendous improvement in our understanding of the scale, diversity, and importance of the gut microbiome. This has been reflected in the form of a revised nomenclature to the more inclusive brain-gut-enteric microbiota axis and a sustained research effort to establish how communication along this axis contributes to both normal and pathological conditions. In this review, we will briefly discuss the critical components of this axis and the methodological challenges that have been presented in attempts to define what constitutes a normal microbiota and chart its temporal development. Emphasis is placed on the new research narrative that confirms the critical influence of the microbiota on mood and behavior. Mechanistic insights are provided with examples of both neural and humoral routes through which these effects can be mediated. The evidence supporting a role for the enteric flora in brain-gut axis disorders is explored with the spotlight on the clinical relevance for irritable bowel syndrome, a stress-related functional gastrointestinal disorder. We also critically evaluate the therapeutic opportunities arising from this research and consider in particular whether targeting the microbiome might represent a valid strategy for the management of CNS disorders and ponder the pitfalls inherent in such an approach. Despite the considerable challenges that lie ahead, this is an exciting area of research and one that is destined to remain the center of focus for some time to come.

Keywords: microbiota, central nervous system, enteric nervous system, irritable bowel syndrome, vagus nerve, inflammation, probiotic, dysbiosis

\section{INTRODUCTION}

Scientific endeavor is increasingly characterized by a multidisciplinary approach to the study of both health and disease. Nowhere is this more evident than in the field of neurogastroenterology where the converging influence of experts across the diverse domains of gastroenterology, psychiatry, microbiology, pharmacology, immunology, and behavioral neuroscience, to name but a few, have helped shape emerging biological themes. Chief among these is the concept of the brain-gut axis, a term which describes the complex bidirectional communication system that exists between the central nervous system (CNS) and the gastrointestinal tract (GIT) and which is vital for maintaining homeostasis (Cryan and O'Mahony, 2011). Spurred in part by the discovery of Helicobacter pylori as a causative agent in ulcer diseases but also by other innovative research in the gastrointestinal sciences (Pandol, 2010; Shanahan, 2010b), there is a growing appreciation of the critical role played by the commensal microbiota, both in our general wellbeing and in the specific functioning of the brain-gut axis. This has been reflected in the form of a revised nomenclature to the more inclusive brain-gut-enteric microbiota axis and a sustained research effort to establish how communication along this axis contributes to both normal and pathological conditions (Rhee et al., 2009).

In this review, we will briefly discuss the critical components of this axis and the methodological challenges that have been presented in attempts to define what constitutes a normal microbiota and chart its temporal development. We examine the approaches that have been taken to elucidate the impact of the enteric microflora on this axis and vice-versa, with reference to the previously elucidated functions of the microbiota as well as an evaluation of exciting new data suggesting a role for the microbiota in the modulation of mood and behavior. Mechanistic insights are provided and the evidence supporting a role for the microbiota in disease states is discussed. The clinical implications are critically evaluated, therapeutic opportunities arising from these findings discussed and future perspectives are provided on this rapidly expanding area of research.

\section{THE BRAIN-GUT-ENTERIC MICROBIOTA AXIS}

The general scaffolding of the brain-gut-enteric microbiota axis includes the CNS, the neuroendocrine and neuroimmune systems, the sympathetic and parasympathetic arms of the autonomic 
nervous system (ANS), the enteric nervous system (ENS), and of course the intestinal microbiota. These components interact to form a complex reflex network with afferent fibers that project to integrative CNS structures and efferent projections to the smooth muscle (O'Mahony et al., 2011). Put simply, through this bidirectional communication network, signals from the brain can influence the motor, sensory, and secretory modalities of the GIT and conversely, visceral messages from the GIT can influence brain function (O'Mahony et al., 2011). This top-down and bottom-up perspective of information flow as well as the detailed structural integration and functioning of the various axis components has been reviewed extensively elsewhere (Mayer, 2011). Less well studied but increasingly appreciated is the potential impact of the enteric microbiota on the alliances within the construct (Rhee et al., 2009; Cryan and O'Mahony, 2011).

\section{MICROBIOTA COMPOSITION AND DEVELOPMENT}

If size matters, then the numerical assessment of the microbiota ensure that it won't be found wanting. The GIT is inhabited with $10^{13}-10^{14}$ microorganisms, a figure thought to be 10 times that of the number of human cells in our bodies and 150 times as many genes as our genome (Gill et al., 2006; Qin et al., 2010). The estimated species number varies greatly but it is generally accepted that the adult microbiome consists of greater than 1000 species (Qin et al., 2010) and more than 7000 strains (Ley et al., 2006a). It is an environment dominated by bacteria, mainly strict anaerobes, but also including viruses, protozoa, archae, and fungi (Gill et al., 2006; Xu et al., 2007). The microbiome is largely defined by two bacterial phylotypes, Bacteroidetes and Firmicutes with Proteobacteria, Actinobacteria, Fusobacteria, and Verrucomicrobia phyla present in relatively low abundance (Eckburg et al., 2005).

The surety with which these quantitative and qualitative descriptions have been advanced belies the methodological difficulty encountered while trying to delineate and enumerate the constituents of a normal microbiota. Culture based analyses, the mainstay of traditional microbiological attempts to define the enteric flora, are only adequate for the minority of the gut microbiota that is amenable to cultivation (Eckburg et al., 2005; Shanahan, 2010a). This problem has largely been circumvented by the use of culture-independent techniques, a portfolio consisting of sequencing based methods, genetic fingerprinting, fluorescently labeled oligonucleotide probes (FISH), quantitative PCR as well as metagenomic approaches (Sekirov et al., 2010; Archie and Theis, 2011). The realization that the secretory and metabolic capability of the microbiome was likely as important as phylotype composition has also led to the use of metabolomic and metaproteomic approaches to improve our understanding of what has been described as the forgotten organ (O'Hara and Shanahan, 2006). Unfortunately, advances in culture methods have not kept pace with the rise of these alternative technologies and a dual-pronged line of attack may be required to complete the circle, a not inconsiderable logistical challenge (Clarke et al., 2009b). Moreover deficits remain to be redressed in relation to the microbial content of the small intestine due to an over-reliance on the analysis of fecal microbial composition (Forsythe et al., 2010).
As our knowledge of the previously unimagined scale of microbial diversity within the gut has expanded, so too has an understanding of its development and longitudinal variation. Colonization of the infant gut commences at birth when delivery exposes the infant to a complex microflora and its initial microbiome has a maternal signature (see Figure 1; Mändar and Mikelsaar, 1996; Mackie et al., 1999; Palmer et al., 2007). The microbiome of unweaned infants is simple with high interindividual variability (McCracken and Lorenz, 2001; Kurokawa et al., 2007; Adlerberth and Wold, 2009). The numbers and diversity of strict anaerobes increase as a result of diet and environment, and after 1 year of age a complex adult-like microbiome is evident (Mackie et al., 1999; Kurokawa et al., 2007; Palmer et al., 2007). Of note is that a western diet is thought to be culpable for the development of a microbiota with a tendency toward an enhanced proinflammatory motif (Greer and O'Keefe, 2011; Wu and Hui, 2011). Despite a significant interpersonal variation in the enteric microbiota, there seems to be a balance that confers health benefits and an alteration in beneficial bacteria can negatively influence the wellbeing of the individual (Cryan and O'Mahony, 2011). Several factors may alter the microbiome such as infection, disease, diet, and antibiotics, but it tends to revert to the stable diversity established in infancy once the threat of the initial distorting factor has subsided (Forsythe et al., 2010). Interestingly, it has been demonstrated that the core microbiota of an aged individual is distinct from that of younger adults (Claesson et al., 2011) and that age related shifts in the composition of the intestinal microbiota are linked to adverse health effects in the elderly host (Woodmansey, 2007).

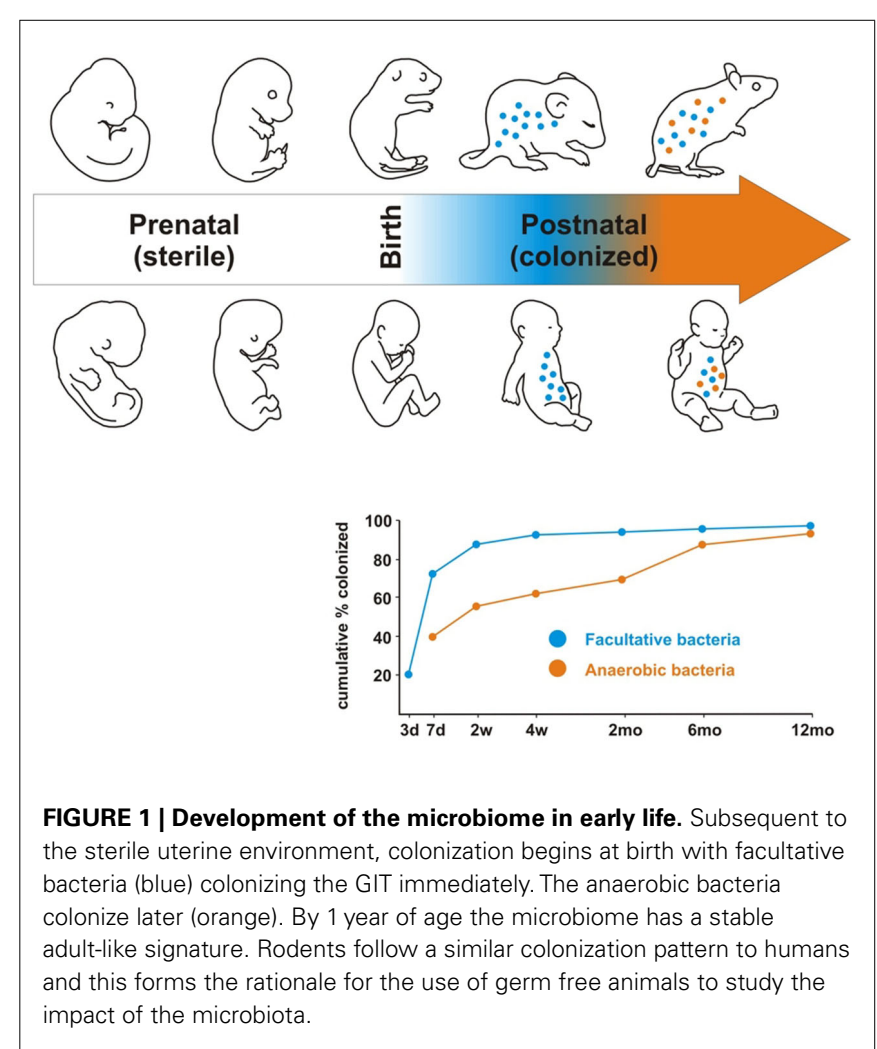




\section{EVALUATING THE ROLE OF THE MICROBIOTA}

Of the varied strategies employed to study the function of the microbiota, perhaps the use of germ-free (GF) animals has offered the most revealing insights. Their use is based on the sterile uterine environment present during prenatal development (Adlerberth and Wold, 2009) with surgical delivery replacing the normal birthing process, thus eliminating the opportunity for post-natal colonization of the GIT (see Figure 1). Subsequent comparison with their conventionally colonized counterparts allows inferences to be drawn regarding the morphological and physiological parameters that may be under the influence of the developing microbiota. However useful the complete absence of an intestinal microbiota may be in proof of principle studies, it is not reflective of real life scenarios. Other approaches which have more validity in this regard involve inducement of a dysbiosis of the enteric flora, either through administration of antibiotics or deliberate infection in preclinical studies (Cryan and O'Mahony, 2011). Broad spectrum antibiotics in particular are known to perturb the microbiome by reducing biodiversity and delaying colonization and are widely used as a method to intentionally alter the microbiome in a reproducible manner (Bennet et al., 2002; Donskey et al., 2003). The use of cell lines, molecular approaches, and isografts have also proved useful in evaluating the role of the microbiota (McCracken and Lorenz, 2001).

\section{FUNCTIONAL RELEVANCE OF THE MICROBIOTA}

GF studies have been pivotal in establishing the structural, protective, and metabolic repertoire of functions that had been assigned to the microbiota even prior to the resurgence in interest in recent years (O'Hara and Shanahan, 2006). The morphological consequences of growing up germ-free were evidenced by the greatly enlarged cecum, reduced intestinal surface area, increased enterochromaffin cell area, smaller Peyer's Patches and smaller villous thickness in these animals compared to conventional controls (Wostmann and Bruckner-Kardoss, 1959; Gordon and BrucknerKardoss, 1961; Abrams et al., 1963; Shanahan, 2002). It was perhaps unsurprising, given these gross structural aberrations, that multiple facets of normal GIT function would also be affected (see Figure 2).

Thus it is known that the microbiota is essential for normal GIT motility, with deficits due in part to perturbations in peristalsis on the back of impaired smooth muscle layer function (Berg,

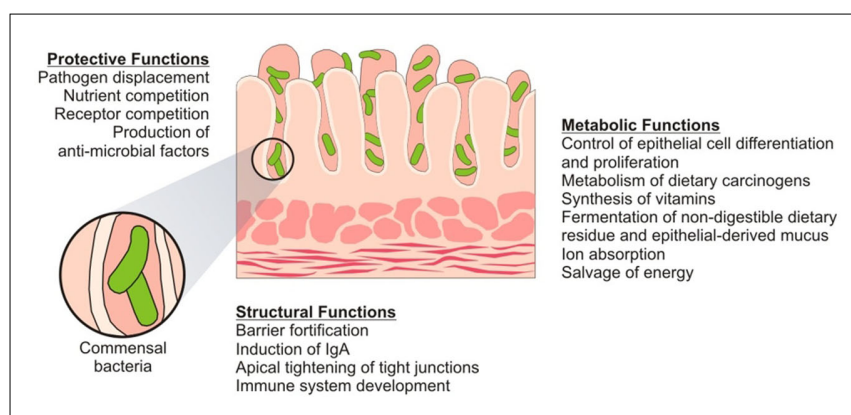

FIGURE 2 | Function of the intestinal microbiome. Commensal bacteria exert a miscellany of protective, structural, and metabolic effects on the intestinal mucosa.
1996; Stappenbeck et al., 2002). It is also clear from early studies that the microbiome is involved in maintenance of barrier function. Intestinal epithelial cell turnover is much slower in GF animals than conventionally reared animals (Abrams et al., 1963). More recent studies substantiate these assertions with demonstrations that commensal flora recognition by toll-like receptors (TLRs) is necessary to induce increased epithelial cell proliferation thus accelerating repair of the epithelial surface following injury (Rakoff-Nahoum et al., 2004). Monoassociation of GF animals with Bacteroides thetaiotaomicron, a representative strain of bacteria from the dominant microbial phyla, up-regulates sprr2a, a gene involved in desmosome maintenance and reinforcement of the intestinal barrier (Hooper et al., 2001). Furthermore, activation of the TLR2 signaling pathway directly enhances intestinal epithelial integrity through translocation of the tight junction protein zonula occludens-1 (ZO-1; Cario et al., 2004). Paneth cells are secretory cells found in small clusters at the base of crypts of Lieberkühn in the epithelium of the small intestine and maintain intestinal homeostasis by directly sensing enteric bacteria at TLRs which trigger the expression of multiple antimicrobial factors thus controlling intestinal barrier penetration by commensal and pathogenic bacteria (Vaishnava et al., 2008). They are known to express and release a wide variety of antimicrobial peptides including $\alpha$-defensins and lysozyme C. but require a complete microbiome to realize a full complement of these peptides (Hooper et al., 2003; Cash et al., 2006; Vaishnava et al., 2008).

GF studies also revealed that the microbiota is essential for the development of the gut associated lymphoid tissue (GALT) and indeed plays a vital part in shaping the immunological repertoire of the GIT with IgA secretion and controlled inflammation being regarded a consequence of bacterial colonization (Mayer, 2003; Quigley, 2008). In comparison to conventionally housed animals, GF animals have decreased plasma cells and IgA, decreased expression of activation markers on intestinal macrophages, decreased MHCII on epithelial cells, decreased nitric oxide, and histamine levels in the small intestine (Gordon, 1959; Beaver and Wostmann, 1962; Glaister, 1973; Moreau et al., 1978; Matsumoto et al., 1992; Mikkelsen et al., 2004; Sobko et al., 2004; Smith et al., 2007). Peyer's patch follicles are reduced in number and size and the mesenteric lymph nodes are smaller, less cellular, and do not have germinal centers in GF animals (Gordon, 1959; Glaister, 1973). However, reconstitution of GF mice with an intestinal microflora is sufficient to restore the mucosal immune system (Umesaki et al., 1995). Moreover, ligands from commensal bacteria such as polysaccharide A, lipopolysaccharide (LPS), and lipoteichoic acid (LTA) influence the normal development and function of the mucosal immune system (Rakoff-Nahoum et al., 2004; Mazmanian et al., 2005). The basic mechanism of the mucosal immune system is innate immunity and its characteristic ability to distinguish potentially pathogenic microbes from harmless antigens is achieved through pattern recognition receptors (PRR). TLRs are present on cells of the innate immune system and recognize characteristic molecules called pathogen associated molecular patterns (PAMPS; Akira and Hemmi, 2003). Pathogen recognition by a particular TLR results in a cascade of events starting with the activation of the NF- $\kappa$ B signaling system 
and resulting in increased cytokine production and $\mathrm{T}$ cell activation (Ulevitch, 1999). However in the absence of the resident enteric flora, key members of the TLR family have low or absent expression profiles in the GIT, thus compromising appropriate immune responses to pathogenic threats (O'Hara and Shanahan, 2006).

The microbiota also has a critical role in supporting normal digestion and host metabolism. There are two main mechanisms by which it can maximize nutrient availability, either by the release of calories from otherwise unavailable oligosaccharides or by modulating absorption (Sekirov et al., 2010). A significant energy source for humans is the bacterial metabolism of dietary fiber to short-chain fatty acids (SCFAs; Macfarlane and Macfarlane, 2003). SCFAs can modulate the host energy balance through Gpr41, a G protein coupled receptor that binds SCFA, and is dependent upon the gut microbiome (Samuel et al., 2008). It is thought that interaction between SCFAs produced by the gut bacteria, and Gpr41 increases circulating levels of PYY, an enteroendocrine hormone that reduces gut motility and thus increases absorption of SCFAs (Samuel et al., 2008). GF animals require a higher caloric intake to maintain the same body weight as conventional animals and are prone to vitamin deficiencies, requiring dietary supplementation with vitamins K and B (Sumi et al., 1977; Wostmann, 1981; Wostmann et al., 1983).

Prevention of colonization by pathogens is achieved in large part through the resident microbiota by competing for nutrients and receptors and production of anti-microbial compounds (Sekirov et al., 2010). Lactobacillus and Bifidobacterium are gram positive bacteria and form two important genera in the microbiome. These bacteria were shown to inhibit listerial infections in vitro. It is thought that Lactobacilli inhibited infection through a combination of acid production and secretion of an unidentified protein while Bifidobacterium inhibition was attributed to an extracellular proteinaceous secreted compound (Corr et al., 2007a). In another study a Lactobacillus salivarius strain was shown to produce a bacteriocin in vivo that could significantly protect mice against infection with the pathogen Listeria monocytogenes (Corr et al., 2007b).

\section{MICROBIOTA AND THE CNS}

It is clear then from the gamut of functions under the influence of the microbiota - regulation of the mucosal immune system, GIT motility, and epithelial barrier function, support for digestion/host metabolism and prevention of colonization by pathogens - that critical components of the brain-gut axis other than the GIT itself might also be subject to manipulation by the microbiome. More specifically, the potential influence of the commensal bacteria on CNS signaling is currently, after a slow start, a burgeoning area of research.

The core neuroendocrine pathway in man is the hypothalamicpituitary-adrenal (HPA) axis and activation of this axis takes place in response to a variety of physical and psychological stressors (Dinan et al., 2006). After much initial speculation, an elegant study by Sudo et al. (2004) provided some insight into the role of the intestinal microbiota in the development of the HPA axis. In GF mice a mild restraint stress induced an exaggerated release of corticosterone and adrenocorticotrophin hormone (ACTH) compared to the specific pathogen free (SPF) controls. The stress response in the GF mice was partially reversed by recolonization with fecal matter from SPF animals and fully reversed by monoassociation with $B$. infantis in a time dependant manner (Sudo et al., 2004). This study clearly demonstrated that the microbial content of the GIT is critical to the development of an appropriate stress response later in life and also that there is a critical window in early life where colonization must occur to ensure normal development of the HPA axis. Sudo et al. (2004) also reported a decrease in brain derived neurotrophic factor (BDNF), a key neurotrophin involved in neuronal growth and survival, and expression of the NMDA receptor subunit 2a (NR2a) in the cortex and hippocampus of GF animals compared to SPF controls.

The encouraging findings from this study prompted further research in this area, especially with a view to establishing a behavioral phenotype and neurochemical profile that might be associated with the gut flora. To date, the most consistent data has been in relation to indices of anxiety. Neufeld et al. (2011), despite reporting an unexplained increase in BDNF mRNA that was contrary to the protein decreases observed in the earlier study, reported a less anxious phenotype for germ free animals in the elevated plus maze (EPM). This behavioral phenotype was replicated in another study with GF animals in both the EPM and the light dark box and associated with an altered gene expression profile in relevant brain regions (Heijtz et al., 2011). Probiotic administration studies also weigh in on the side of a role for the microbiota in anxiety-like behaviors with, for example, administration of $L$. helveticus R0052 and B. longum R0175 taken in combination displaying anxiolytic-like activity in rats (Messaoudi et al., 2011). Moreover, a recent study reported that chronic treatment with the probiotic $L$. rhamnosus (JB- 1 ) over 28 days produced animals with lower levels of stress-induced corticosterone and reduced depressive behaviors in the forced swim test in addition to a less anxious phenotype in the EPM. The L. rhamnosus $(J B-1)$ treated animals also showed alterations of $\mathrm{GABA}_{\mathrm{B} 1 \mathrm{~b}} \mathrm{mRNA}$ in the brain with increased expression in cortical regions and decreased expression in the hippocampus, amygdala, and locus coeruleus as well as reduced $\mathrm{GABA}_{\mathrm{A} \alpha 2}$ mRNA expression in the prefrontal cortex and amygdala and increased $\mathrm{GABA}_{\mathrm{A \alpha 2}}$ in the hippocampus. Interestingly the authors demonstrated that vagotomized mice did not display the neurochemical and behavioral effects of this bacterium, thus implicating the vagus nerve in the direct communication between the bacteria and the brain (Bravo et al., 2011). A role for the gut microbiota in pain perception has also been proposed (Forsythe et al., 2010), with, for example, one study demonstrating that specific Lactobacillus strains could induce the expression of $\mu$ opioid and cannabinoid receptors in intestinal epithelial cells and mimic the effects of morphine in promoting analgesia (Rousseaux et al., 2007).

A strategy employing antibiotic-induced dysbiosis of the microbiome, in this case a cocktail consisting of neomycin, bacitracin, and the antifungal agent pimaricin, resulted in mice which displayed less anxiety-like behaviors in the both the step down box and the light/dark box test. Interestingly the authors also reported altered protein levels of BDNF in the amygdala and hippocampus and that discontinuation of the antibiotic cocktail 
restored the normal behavioral profile of the animals (Bercik et al., 2011). Similarly perturbation of the microbiota by means of an infectious agent like Citrobacter rodentium has been shown to increase anxiety-like behavior in mice $7-8 \mathrm{~h}$ post infection as measured in the hole board open field apparatus (Lyte et al., 2006) and to produce stress-induced memory dysfunction 10 and 30 days post infection (Gareau et al., 2011). Moreover, memory dysfunction was prevented by daily administration of a probiotic cocktail and when GF mice were infected they developed memory dysfunction regardless of whether they were stressed or not.

\section{INFLUENCE OF THE BRAIN ON THE MICROBIOME}

Although the bulk of research to date has focused on the impact of the microbiota on CNS function, there is also research to suggest that the brain can alter the microbiome. Signaling molecules released into the gut lumen from cells in the lamina propria that are under the control of the CNS can result in changes in gastrointestinal motility and secretion as well as intestinal permeability, thus altering the GIT environment in which the bacteria reside (Rhee et al., 2009). Stress also induces permeability of the gut allowing bacteria and bacterial antigens to cross the epithelial barrier and this can activate a mucosal immune response which in turn alters the composition of the microbiome (Kiliaan et al., 1998). Acute stress was shown to cause an increase in colonic paracellular permeability which involved mast cells and overproduction of IFN- $\gamma$ with decreased expression of ZO-2 and occludin mRNA (Demaude et al., 2006). The psychological components of social stress was shown to facilitate the translocation of indigenous bacteria into the host (Bailey et al., 2006). Other studies have shown that stress hormones promoted the growth of non-pathogenic isolates of Escherichia coli as well as the pathogenic E. coli 0157:H7 strain via interactions with host catecholamines such as adrenaline and noradrenaline (Freestone et al., 2002, 2003). Different psychological stressors are known to alter the composition of the microbiome by modulating the composition of total biomass in infants (Rhee et al., 2009). Prenatal stressors have been shown to alter the microbiome in rhesus monkeys by reducing the overall numbers of Bifidobacteria and Lactobacilli (Bailey et al., 2004). Maternal separation, an early life stressor, caused a significant decrease in fecal Lactobacilli on day 3 post separation, which returned to baseline by day 7 as assessed by enumeration of total and gram-negative aerobic and facultative anaerobic bacterial species (Bailey and Coe, 1999). However, early life stress can also have long term effects on the microbiome. Analysis of the $16 \mathrm{~S}$ rRNA diversity in adult rats exposed to maternal separation for $3 \mathrm{~h}$ per day from post-natal days $2-12$ revealed a significantly altered fecal microbiome when compared to the non-separated control animals (O'Mahony et al., 2009).

\section{MECHANISMS OF ACTION}

A number of mechanisms have been proposed through which the intestinal communal microflora might influence ENS and CNS signaling, including both neural and humoral routes as well as direct and indirect modes of action (see Figure 3; Forsythe et al., 2010). Perhaps the best evidence to date comes from a novel recent

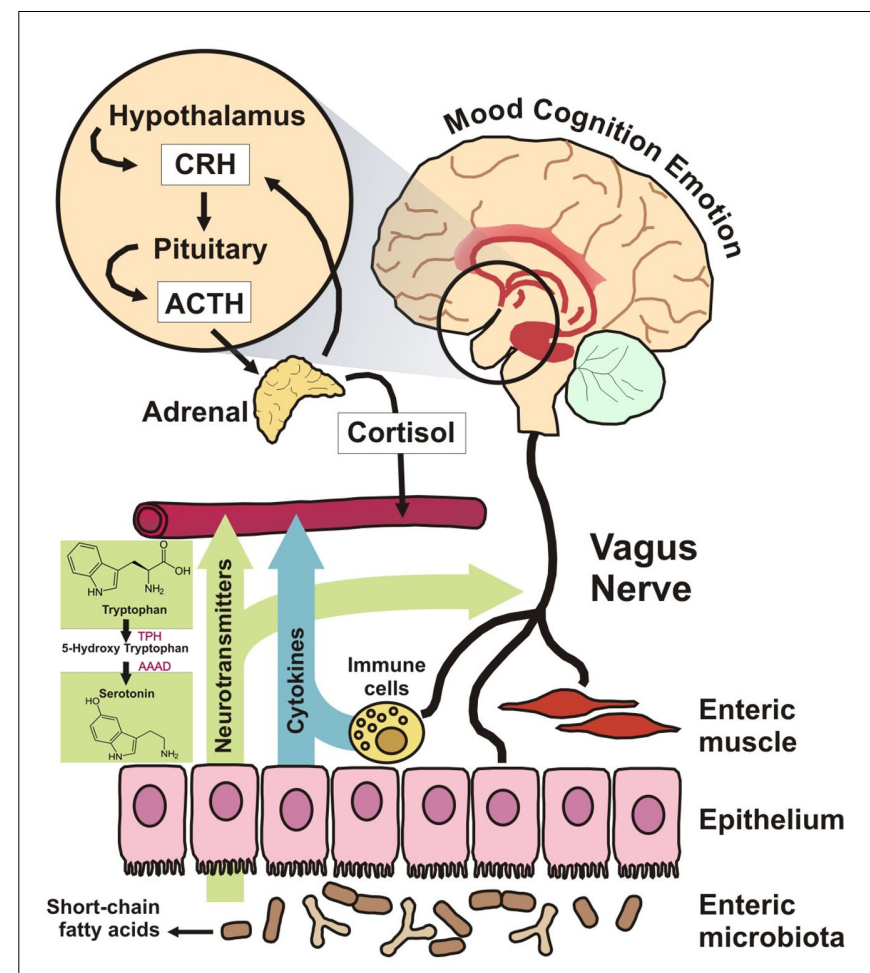

FIGURE 3 | Proposed mechanisms of action. There are a variety of proposed mechanisms, including both humoral and neural routes, through which the microbiota can modulate signaling along the brain-gut axis. For example, recent studies suggest a role for both the vagus nerve and modulation of systemic tryptophan levels in relaying the influence of both resident and exogenous microflora along this bidirectional communication axis.

study which conclusively implicated the vagus nerve in the direct communication observed between the bacteria and the brain (see earlier sections for detailed description; Bravo et al., 2011). Further studies are required to clarify the precise route though which the administered probiotic interacts with the vagus nerve but in any case this study confirmed a mechanism many had previously suggested as a likely contender (Cryan and O'Mahony, 2011). Other potential mechanisms of action include neurotransmitter modulation. B. infantis 35624, for example, has been shown to induce an elevation in plasma tryptophan levels, a precursor to serotonin $(5-\mathrm{HT})$ which is a key neurotransmitter within the brain-gut axis, in Sprague-Dawley rats (Desbonnet et al., 2008). Since CNS tryptophan concentrations are largely dependant on peripheral availability and the enzymatic machinery responsible for the production of 5-HT is not saturated at normal tryptophan concentrations (Ruddick et al., 2006), the implication here is that the microbiota might play some role in the regulation of CNS as well as ENS 5-HT synthesis. This effect is potentially mediated by the effect of the microbiota on the expression of indoleamine2,3-dioxygenase, a key enzyme in the physiologically dominant kynurenine pathway of tryptophan degradation (Forsythe et al., 2010). Of course multiple mechanisms are possible and indeed likely, given the strain specific effects that have been observed in many probiotic studies to date (Quigley, 2008). 


\section{MICROBIOTA IN DISEASE}

Since the microbiota is involved in maintaining homeostasis and wellbeing, the proposition that it may also be involved both in gastrointestinal and systemic illnesses is a logical one (see Figure 4). As might be expected given the importance of the microbiota in supporting host digestion and metabolism, obesity has been considered as an illness with a potential microbial basis. It has been defined as a medical condition in which excess body fat has accumulated to produce adverse effects on health, leading to increased health problems and potentially a reduced life expectancy (Haslam and James, 2005). The incidence of obesity is increasing in both developed and developing countries and has become a worldwide burden upon health care systems (Bloom et al., 2008). Some of the most convincing evidence comes from studies in GF animals which have shown them to be naturally leaner than their SPF counterparts and colonization of adult GF mice with a normal microbiota from the cecum of conventionally raised animals produces a $60 \%$ increase in body fat content and insulin resistance within 14 days despite reduced food intake (Bäckhed et al., 2004). GF mice are resistant to diet induced obesity but when colonized with fecal flora from SPF mice they gained weight due to altered fatty acid metabolism (Bäckhed et al., 2007). Other studies have shown that the $o b / o b$ mouse, a strain of mouse genetically predisposed to obesity, had a 50\% decrease in the abundance of Bacteroidetes and a proportional increase in Firmicutes when compared to the lean wild type and heterozygotic

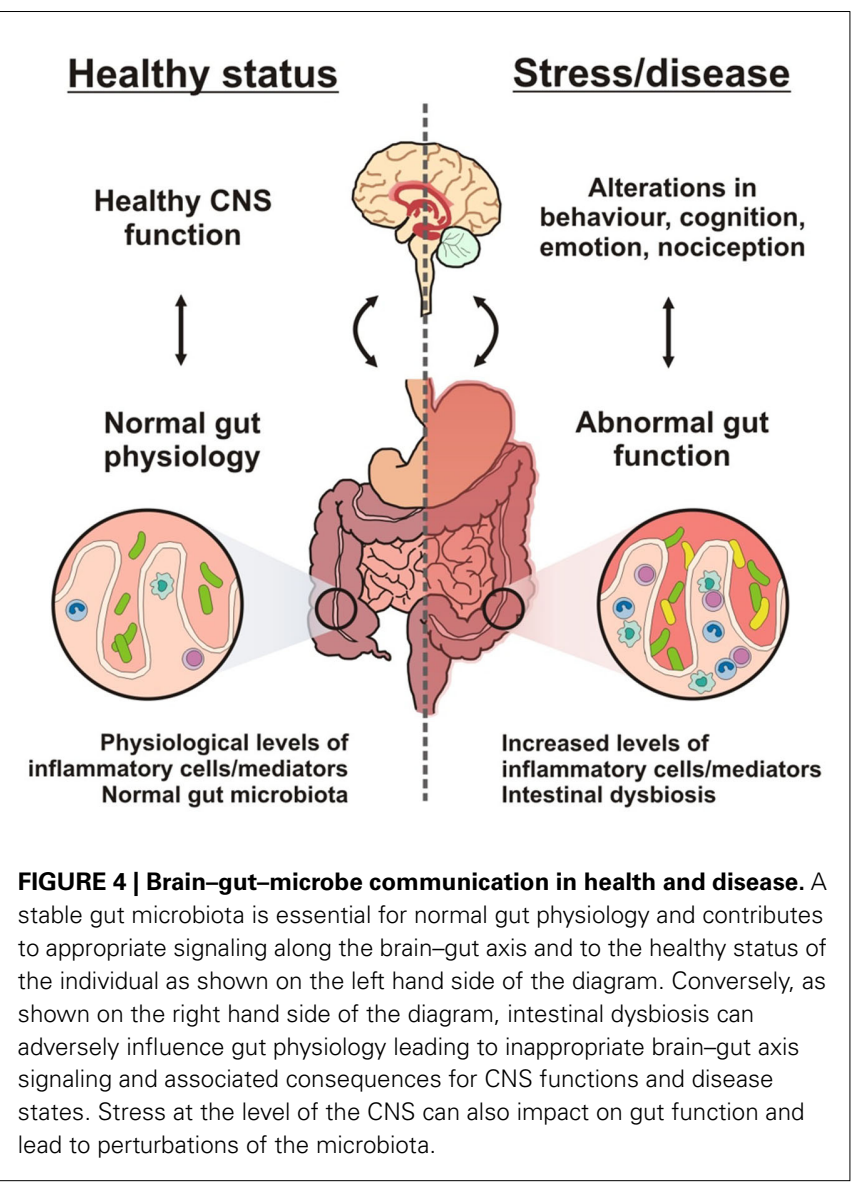

controls (Ley et al., 2005). In humans, when the fecal microbiota of obese individuals was compared to lean controls there were fewer Bacteroides and more Firmicutes in the obese group. However, over time on a calorie restricted diet the relative abundance of Bacteroidetes increased and the abundance of Firmicutes decreased (Ley et al., 2006b). While these studies do offer some support for a purturbations of the resident flora in the accumulation of excess fat, microbial influences should not be considered in isolation: obesity is a multifactorial condition that also involves strong genetic factors, hypothalamic dysfunction, and an increase in the consumption of energy-dense food (Schellekens et al., 2010).

Less intuitive is a potential role for the microbiota in the development of autism, a developmental disorder that appears in the first 3 years of life and affects the brain's normal development of social and communication skills (American Psychiatric Association, 2000). Interestingly in a study of 58 autism patients $>90 \%$ had gastrointestinal problems compared to none in the control group (Parracho et al., 2005). Although the underlying etiology of autism is not well understood, late onset autism is hypothesized to be caused by extensive use of antibiotics with an association with Trimethoprim/sulfamethoxazole antibiotic treatment (Bolte, 1998; Finegold et al., 2002). There is evidence to support alterations of the fecal microbiota in patients with autism, with an increase in several subtypes of Clostridium (Song et al., 2004; Finegold et al., 2010) and in the majority of cases treatment with vancomycin, an antibiotic that targets gram positive anaerobes and is minimally absorbed by the GIT, can improve symptoms (Sandler et al., 2000). It is further hypothesized that Clostridium spores are responsible for relapse after completion of the antibiotic treatment and that a treatment targeting these spores alleviates symptoms for longer periods (Finegold, 2008).

Within the realm of gastrointestinal disorders, inflammatory bowel disease (IBD), which includes the two distinct disease patterns of ulcerative colitis (UC) and Crohn's disease (CD; Lichtenstein, 2000; Blumberg and Strober, 2001; Podolsky, 2002; MacDonald and Monteleone, 2005), has attracted attention as a disorder with an aberrant GIT microbial signature (Shanahan, 2004). Several studies have shown altered gut microbiota in patients with IBD although it is not clear whether these changes are responsible for causing disease or are the result of inflammatory responses and extensive tissue changes in the GIT (Macfarlane et al., 2009). This was not clarified by a study which showed that the microbiome was also significantly altered in mucosal biopsies taken from inflamed compared to healthy sites (Walker et al., 2011). The changes in the microbiota are characterized by increases in Proteobacteria and a decline in Firmicutes and Bacteroidetes (Frank et al., 2007; Walker et al., 2011). This altered microbiota is also evident in animal models of inflammation relevant to IBD with a dramatic increase in the Proteobacteria classes of bacteria evident (Lupp et al., 2007). Interestingly although a Bacteroides species has been shown to colonize both genetically IBD susceptible and non-susceptible mice to the same extent, it only engendered disease in the susceptible animals (Bloom et al., 2011). Furthermore, in terms of exogenous microbial threats, the frequency of Clostridium difficile has been shown to be higher in IBD and may trigger relapse where the disease is established but in remission (Clayton et al., 2009). 
Although the pathogenesis of IBD is still not completely understood, it is well recognized that psychological stress, a factor which can perturb the microbiota, exacerbates the condition (Mawdsley and Rampton, 2006; Reber, 2011). However it should be recognized that IBD has a complex and multifaceted etiology, involving environmental and genetic factors which cause dysregulation of the mucosal immune system (Andus and Gross, 2000; MacDonald and Monteleone, 2005). Thus, while the microbiota might not be the sole driving force in IBD, most consider that hostflora interactions underpin the disorder, especially in genetically susceptible individuals (Shanahan, 2005; Melgar and Shanahan, 2010).

The best evidence to date for the involvement of the microbiota in disease states comes from irritable bowel syndrome (IBS), a prototypical stress-related brain-gut axis disorder. IBS is the most common functional gastrointestinal disorder (FGID) encountered in clinical settings (Camilleri, 2001), affecting an estimated 10$15 \%$ of the general population in Western Europe and North America (Quigley, 2011). It is characterized by the presence of abdominal pain or discomfort, an alteration in bowel habit, and the absence of reliable biomarkers (Thompson et al., 1999; Drossman et al., 2002; Clarke et al., 2009b). A number of strands of evidence support a role for the microbiota in the pathophysiology of IBS and chief among these is the supporting data for post-infectious IBS (PI-IBS), a term which describes the development of IBS following an episode of bacteriologically confirmed gastroenteritis (Quigley, 2009; Sarna, 2011). This phenomenon is now well documented (Gwee et al., 1999, 2003; Rodríguez and Ruigómez, 1999; Marshall et al., 2006, 2007) and prospective studies showing that the risk of developing PI-IBS is in the order of $3-36 \%$ following an enteric infection with the precise incidence depending on the infecting organism (Spiller and Garsed, 2009). The highest reported incidence of PI-IBS was associated with the Walkerton outbreak with $36 \%$ of individuals showing symptoms of IBS 2 years after infection with both Campylobacter jejuni and E. coli 0157:H7 (Marshall et al., 2006). A mechanistic perspective has been provided by a number of studies which found a persistent elevation in rectal mucosal enteroendocrine cells, T-lymphocytes and gut permeability following the infectious insult in subjects who went on to develop IBS (Spiller et al., 2000; Dunlop et al., 2003). These studies are regarded as important indicators of a link between alterations in the microbiota and mucosal inflammation in IBS (Quigley, 2009).

On the basis that immunological changes in IBS might result from exposure to exogenous bacterial challenge, studies supporting the low grade inflammation that has so frequently been reported in IBS are also taken as evidence of a role for the microbial perturbations in the disorder (Clarke et al., 2009b; Quigley, 2009). Persistent low grade inflammation is a characteristic of PIIBS (Gwee et al., 1999) and these patients exhibit greater IL-1 $\beta$ mRNA expression, both during and after the infection, compared with individuals who do not develop PI-IBS (Gwee et al., 2003). IBS patients with normal histology had increased intraepithelial lymphocytes and CD3 + and CD25+ cells in the lamina propria (Chadwick et al., 2002). Increased CD25+ cells in IBS suggests an antigen challenge and these cells are preventing " $\mathrm{a}$ more florid inflammatory response" (Collins, 2002). There are increased numbers of activated mast cells in colonic biopsies from IBS patients and a direct correlation between proximity of the mast cells to neurons and pain severity (Barbara et al., 2004). Cenac et al. (2007) demonstrated increased proteolytic activity in colonic washes from IBS compared with control patients while the analysis of TLR expression in colonic biopsies has demonstrated increased expression of TLR4 and TLR5 and decreased levels of TLR7 and TLR8 in IBS patients (Brint et al., 2011).

Others have investigated the involvement of the systemic immune system on the basis that it might reflect mucosal disturbances. In a study of 78 IBS patients O'Mahony et al. (2005) demonstrated an abnormal IL-10/IL-12 ratio in stimulated peripheral blood mononuclear cells (PBMCs), indicating a proinflammatory, Th-1 state. Liebregts et al. (2007) showed an enhanced proinflammatory cytokine release (TNF- $\alpha$, IL- $1 \beta$, IL-6) in LPS stimulated PBMCs from IBS patients. In another study, baseline plasma proinflammatory cytokines IL-6, IL-6R, and IL-8 were elevated in IBS and accompanied by overactivation of the HPA axis (Dinan et al., 2006). Indeed elevations in systemic proinflammatory mediators have repeatedly being demonstrated in both clinical datasets and reports from animal models of the disorder (Dinan et al., 2008; Clarke et al., 2009a, 2010; O’Mahony et al., 2009; Scully et al., 2010). What is not clear is whether they truly represent a disturbance at mucosal sites and this remains a subject in need of further investigation. Interestingly it has recently been reported that IBS patients have a distinct pattern of exaggerated peripheral TLR activity as indicated by measurements of cytokine production following whole blood stimulations (McKernan et al., 2011).

The qualitative alterations and temporal instability that have been reported in the enteric flora in IBS cohorts, summarized in Table 1, is taken as further evidence of an involvement in disease pathophysiology and is backed up by data from animal models of the disorder (O'Mahony et al., 2009; Quigley, 2009). While it is unclear at present is whether these changes in the flora are primary or secondary and although they have proven difficult to reproduce in many cases, there are certainly routes through which they could impact on symptom pathogenesis (Quigley, 2009). Quantitative alterations in the flora, which have centered around claims of small intestinal bacterial overgrowth (SIBO) and have in some cases formed the proposed basis for the efficacy of antibiotics such as rifaximin in IBS, are more controversial with critics questioning both the specificity and validity of the measurements (Quigley, 2007). This is also contrary to the view that antibiotics might be a risk factor for the development of IBS (Collins et al., 2009).

\section{THERAPEUTIC OPPORTUNITIES}

Although modulation of the microbiota has primarily been a source of evidence for the functional importance of the commensal load in health, the swell of studies implicating our resident microflora in disease states such as IBS means that this could also be a strategy with therapeutic potential. There is mounting evidence to support the use of antibiotics, prebiotic substances, and probiotics with the latter option in particular enjoying some success as a treatment option in IBS (Quigley, 2008; Rhee et al., 2009). Thus, although the effects appear to be strain specific, cumulative data from the clinical trials to date suggest a role for certain 
Table 1 | Studies which have shown altered fecal and mucosal microbiome in disease states.

\begin{tabular}{|c|c|c|c|c|}
\hline Group & Method, microbiota analyzed & Diagnostic criteria and subjects & Finding & Reference \\
\hline \multirow[t]{5}{*}{ IBS } & Q-PCR, fecal microbiome & $\begin{array}{l}\text { Rome II, } n=27 \\
\text { BS-D }(n=12), \text { IBS-C }(n=9) \\
\text { IBS-A }(n=6)\end{array}$ & $\begin{array}{l}\downarrow \text { Lactobacillus spp. in IBS-D subjects } \\
\uparrow \text { Veillonella spp. in IBS-C }\end{array}$ & $\begin{array}{l}\text { Malinen } \\
\text { et al. (2005) }\end{array}$ \\
\hline & $\begin{array}{l}\text { Culture/DGGE, fecal } \\
\text { microbiome }\end{array}$ & $\begin{array}{l}\text { Rome II, } n=26 \\
\text { BS-D }(n=12), \text { IBS-C }(n=9) \\
\text { IBS-A }(n=5)\end{array}$ & $\begin{array}{l}\text { Increased number of aerobes in IBS patients } \\
\text { Temporal instability in IBS patients revealed by DGGE }\end{array}$ & $\begin{array}{l}\text { Mättö et al. } \\
\text { (2005) }\end{array}$ \\
\hline & & No sub-typing & $\begin{array}{l}\text { Significantly more variation in microbiota of healthy } \\
\text { volunteers than that of IBS patients }\end{array}$ & \\
\hline & $\begin{array}{l}\mathrm{FISH}, \text { fecal and duodenal } \\
\text { microbiome }\end{array}$ & $\begin{array}{l}\text { Rome II, } n=41 \\
\text { IBS-D }(n=14) \text { IBS-C }(n=11) \\
\text { IBS-A }(n=16)\end{array}$ & $\begin{array}{l}\downarrow \text { Bifidobacteria in IBS subjects compared to healthy } \\
\text { controls }\end{array}$ & $\begin{array}{l}\text { Kerckhoffs } \\
\text { et al. (2009) }\end{array}$ \\
\hline & Q-PCR, fecal microbiome & $\begin{array}{l}\text { Rome II and III, } n=26 \\
\text { IBS-D }(n=8) \text { IBS-C }(n=11) \text { IBS-A } \\
(n=7)\end{array}$ & $\uparrow$ Veillonella and Lactobacillus in IBS & $\begin{array}{l}\text { Tana et al. } \\
(2010)\end{array}$ \\
\hline \multirow[t]{4}{*}{ IBD } & $\begin{array}{l}\text { FISH adapted to flow } \\
\text { cytometry, fecal microbiota }\end{array}$ & $\begin{array}{l}\text { Active } \mathrm{CD}(n=13) \\
\text { Active UC }(n=13) \\
\mathrm{IC}(n=5), \mathrm{HS}(n=13)\end{array}$ & $\begin{array}{l}\text { Clostridium coccoides was reduced in UC } \\
\text { C. leptum group was reduced in } \mathrm{CD} \\
\text { Bacteroides group was more abundant in IC }\end{array}$ & $\begin{array}{l}\text { Sokol et al. } \\
\text { (2006) }\end{array}$ \\
\hline & $\begin{array}{l}\text { T-RFLP analysis } 16 \mathrm{~S} \text { rRNA } \\
\text { gene, Q-PCR, ileal and rectal } \\
\text { biopsies }\end{array}$ & $\begin{array}{l}\text { Monozygotic twin pairs that } \\
\text { were discordant }(n=6) \text { or } \\
\text { concordant }(n=4) \text { for } \mathrm{CD}, \mathrm{HS} \\
(n=6)\end{array}$ & $\begin{array}{l}\text { Predominantly ileal CD vs. co-twins and CD localized } \\
\text { in the colon } \\
\downarrow \text { Faecalibacterium prausnitzii } \\
\uparrow \text { Escherichia coli }\end{array}$ & $\begin{array}{l}\text { Willing et al. } \\
\text { (2009) }\end{array}$ \\
\hline & $\begin{array}{l}16 \mathrm{~S} \text { rRNA gene sequencing, } \\
\text { mucosal biopsies }\end{array}$ & $\begin{array}{l}\text { Inflamed and non-inflamed } \\
\text { intestinal tissue from } 6 \mathrm{CD} \\
(n=12), 6 \cup \mathrm{UC}(n=12), \mathrm{HS}(n=5)\end{array}$ & $\begin{array}{l}\downarrow \text { Mucosal microbial diversity in IBD } \\
\downarrow \text { Firmicutes in IBD samples and } \uparrow \text { Bacteroidetes } \\
\uparrow \text { Enterobacteriaceae in CD only significant } \\
\text { differences in microbial community structure between } \\
\text { inflamed and non-inflamed mucosal sites }\end{array}$ & $\begin{array}{l}\text { Walker et al. } \\
\text { (2011) }\end{array}$ \\
\hline & $\begin{array}{l}\text { rRNA sequence analysis and } \\
\text { Q-PCR }\end{array}$ & $\begin{array}{l}\mathrm{UC}(n=61), \mathrm{CD}(n=68) \\
\mathrm{HS}(n=61)\end{array}$ & $\begin{array}{l}\downarrow \text { Bacteroidetes and Lachnospiraceae in IBD } \\
\uparrow \text { Actinobacteria and Proteobacteria in IBD }\end{array}$ & $\begin{array}{l}\text { Frank et al. } \\
\text { (2007) }\end{array}$ \\
\hline
\end{tabular}




\section{Table 1 | Continued}

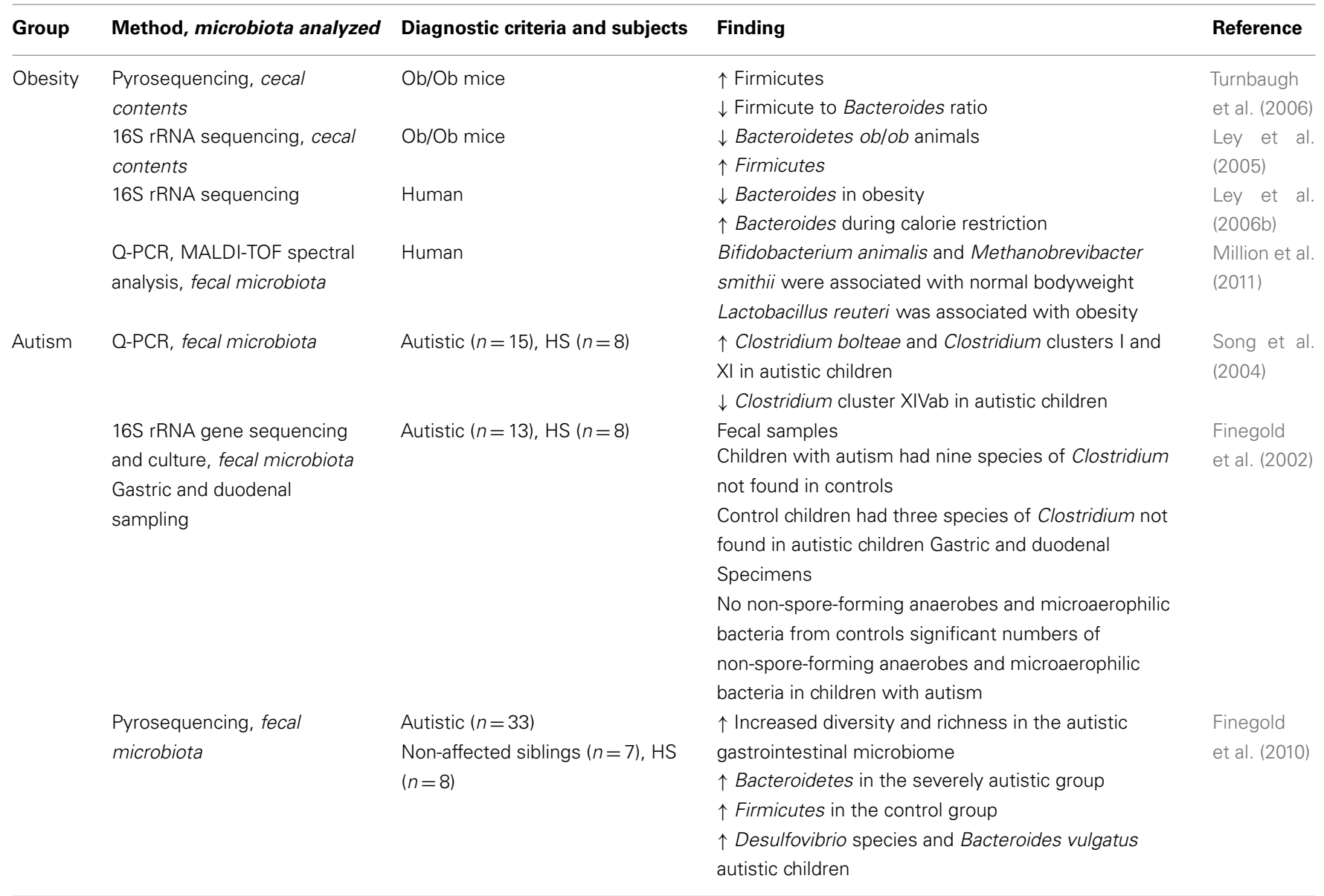

IBS-D, diarrhea predominant IBS; IBS-C, constipation predominant IBS; IBS-A, alternating IBS; UC, ulcerative colitis; $C D$, Crohn's disease; IC, infectious colitis; HS, healthy subjects; DGGE, denaturing gradient gel electrophoresis; Q-PCR, quantitative PCR; FISH, fluorescent in situ hybridization; T-RFLP, terminal restriction length polymorphism.

probiotic therapies in the alleviation of key symptoms in IBS (Abdominal pain/discomfort, bloating/distension, alterations in defecatory function; Moayyedi et al., 2008; Brenner et al., 2009; Whorwell, 2009).

Recent research supporting a role for the microbiota in maintaining normal brain function offers the intriguing possibility that the therapeutic targeting of the gut microbiome might be a viable strategy in the treatment of CNS disorders (Forsythe et al., 2010). Some validation for this approach can be seen in the results of a recent study which demonstrated beneficial psychological effects in healthy human volunteers following administration of a combination of L. helveticus R0052 and B. longum R0175 (Messaoudi et al., 2011). However this field of research is still in its infancy with few studies exploring the concept of microbial targeting of the GIT under pathological conditions of the CNS. Nevertheless, studies that have employed this strategy have generated encouraging results. B. infantis 35624 treatment, for example, was shown to normalize immune responses, reverse behavioral deficits in the forced swim test, and restore basal noradrenaline concentrations in the brainstem of adult rats subjected to the early life stress of maternal separation, an animal model of brain-gut axis dysfunction (Desbonnet et al., 2010; O'Mahony et al., 2011). Of further interest is that a preclinical study using the same probiotic found that CRD-induced visceral pain behaviors were significantly reduced in the viscerally hypersensitive WistarKyoto rat strain (McKernan et al., 2010). L. paracasei NCC2461 administration has also shown efficacy in reducing visceral hypersensitivity in a mouse preclinical model of IBS (Verdu et al., 2006).

Few studies have made an attempt to unravel the mystery surrounding the mechanism of action of probiotics. However a number of theories exist, many of which relate to the previously elucidated role of the microbiota in health. The possibility that the administered probiotic might restore the distorted bacterial flora to one resembling that of healthy individuals is partially supported by a study demonstrating exactly such a phenomenon with a multispecies probiotic preparation previously shown to be effective in the treatment of IBS (Kajander et al., 2005; Lyra et al., 2010). Similarly alterations in the fecal metabolome following administration of an alternative probiotic preparation were linked to its previously demonstrated efficacy (Hong et al., 2009, 2011). However experts in the field consider such a mechanism, 
along with the assumption of competition with and exclusion of pathogens, to be overly simplistic and undermined by an incomplete knowledge of what constitutes a "normal" microbiome (Quigley, 2009).

The notion that efficacious probiotic strains might exert their beneficial effects through modulation of host immunity is gaining traction, especially in the light of the expanding repertoire of studies supporting a low grade inflammation in IBS (Clarke et al., 2009b). Of the strains evaluated, B. Infantis 35624 has been shown to normalize abnormal IL-10/IL-12 ratios in addition to showing efficacy in treatment of the disorder (O'Mahony et al., 2005). That certain probiotics might work by enhancing barrier function and motility has also been considered and is supported primarily by data from Ussing chamber studies. B. breve C50 and its soluble factors have been shown to alleviate chloride secretion in human intestinal epithelial cells (Heuvelin et al., 2009). Bioactive peptide factors secreted by probiotics have been shown to enhance epithelial cell barrier function both in vitro and in vivo (Ewaschuk et al., 2008). Pretreatment with a probiotic mixture containing L. helveticus and L. rhamnosus was shown to prevent bacterial translocation and improve intestinal barrier function in rats following chronic psychological stress (Zareie et al., 2006). Similarly, L. Plantarum $299 \mathrm{~V}$ was shown to inhibit Escherichia coli-induced intestinal permeability (Mangell et al., 2002). The involvement of the vagus nerve is also considered likely in the light of recent studies (Bravo et al., 2011; Cryan and O'Mahony, 2011). In reality the mechanism of action is likely to be multifactorial with particular strains exerting their influence either though one or more of the modes outlined above or via a yet unidentified means.

Despite the demonstrated efficacy of microbiota manipulation in clinical disorders of the GIT, the potential utility of the strategy in the treatment of CNS disorders as gleaned from preclinical data and an improved understanding of the mechanisms involved, a number of caveats still exist surround this approach generally. One such limitation is the mixed results that have been obtained in organic disorders of the GIT such as IBD where controlled trials in $\mathrm{CD}$ have generally been disappointing as against the more favorable results in UC (Shanahan, 2010b). There is also a paucity of data pertaining to the long term effects of microbiome manipulation although it is encouraging to note that a trial with a multispecies probiotic preparation conducted over 5 months showed major benefits for both distension and abdominal pain in conjunction with a stabilization of the microbiota and was completed without any adverse effects (Kajander et al., 2008). It is also important to note the potential benefits of a treatment option with an enviable safety record and negligible toxicity profile compared to conventional pharmacological approaches (Kopp-Hoolihan, 2001; Parvez et al., 2006). Regulatory hurdles also need to be cleared with the current classification of probiotics as food supplements limiting sanctioned use to healthy populations and functional claims over recommendations for application to the treatment of disease states (Marteau, 2010). Even these functional claims are the subject of controversy with agencies like the European Food Safety Authority (EFSA) in disagreement with advocates of probiotics over what constitutes solid scientific evidence for a particular health claim (Guarner et al., 2011). In reality we are probably quite some way from where this will be a serious issue for the application of microbiome manipulation to the treatment of specific CNS disorders but it is already a major impediment facing those who are currently seeking to use the approach for gastrointestinal afflictions.

\section{CONCLUSION AND FUTURE PERSPECTIVES}

The microbiome has assumed its rightful position as a critical component of the brain-gut axis and a key factor in both health and disease, a fact reflected in current research efforts. Previously determined functions of the microbiota have been bolstered with exciting new studies highlighting its potential involvement in a range of disorders as well as its impact on behavior and mood at the level of the CNS. Recent findings raise the possibility that therapeutic targeting of the microbiome might be an effective treatment strategy for specific disorders of the CNS. This needs to be tempered by the realization that we are still some way from being able to completely differentiate a normal microbiota from that present in disease or recognizing how its individual components and collective signature are critical for health. Furthermore although recent mechanistic insights have provided a solid platform for future studies, an advanced understanding of the interactions that occur is still lacking and warrants further research. Whether the approach of microbiome manipulation will evolve into a therapy in its own right or become an adjuvant to conventional therapy is also still unclear (Aragon et al., 2010). While this will involve clarification on the specific assessment criteria for successful health claims by agencies like FDA and EFSA, it also remains to be seen whether probiotic manufacturers will be willing to subject their products to assessment by the rigorous clinical trials that would be necessary for specified use of their products in the treatment of disease states. In this context, supporting gut health through microbiota supplementation with a view toward positively influencing mental status represents a putative preventative strategy worth following (Bischoff, 2010). In addition to consideration of the microbiome as a therapeutic target, we also need to direct more efforts toward mining its metabolites for putative drugs, a strategy that has already paid some dividends (Shanahan, 2010a). It is unmistakable that brain-gutmicrobiome communication in health and disease will continue to occupy the minds of researchers and that the multidisciplinary approaches that have brought us thus far will be evident in meeting the exciting challenges that lie ahead. The likelihood is that we have only seen the tip of the iceberg in this rapidly expanding area of research.

\section{ACKNOWLEDGMENTS}

The Alimentary Pharmabiotic Centre is a research centre funded by Science Foundation Ireland (SFI), through the Irish Government's National Development Plan. The authors and their work were supported by SFI (grant nos. 02/CE/B124 and 07/CE/B1368) and by GlaxoSmithKline. Gerard Clarke is in receipt of a research grant from the American Neurogastroenterology and Motility Society (ANMS). The authors would like to thank Dr. Marcela Julio for preparing the images used in this review (http://www.facebook.com/imagenesciencia). 


\section{REFERENCES}

Abrams, G. D., Bauer, H., and Sprinz, H. (1963). Influence of the normal flora on mucosal morphology and cellular renewal in the ileum. A comparison of germ-free and conventional mice. Lab. Invest. 12, 355-364.

Adlerberth, I., and Wold, A. E. (2009). Establishment of the gut microbiota in Western infants. Acta Paediatr. 98, 229-238.

Akira, S., and Hemmi, H. (2003). Recognition of pathogen-associated molecular patterns by TLR family. Immunol. Lett. 85, 85-95.

American Psychiatric Association. (2000). "Diagnostic criteria for 299.00 Autistic Disorder," in Diagnostic and Statistical Manual of Mental Disorders. 4th, text revision (DSM-IV-TR). Washington DC: American Psychiatric Association.

Andus, T., and Gross, V. (2000). Etiology and pathophysiology of inflammatory bowel disease - Environmental factors. Hepatogastroenterology 47, 29-43.

Aragon, G., Graham, D. B., Borum, M., and Doman, D. B. (2010). Probiotic therapy for irritable bowel syndrome. Gastroenterol. Hepatol. (N. Y.) 6, 39-44.

Archie, E. A., and Theis, K. R. (2011). Animal behaviour meets microbial ecology. Anim. Behav. 82, 425-436.

Bäckhed, F., Ding, H., Wang, T., Hooper, L. V., Koh, G. Y., Nagy, A., Semenkovich, C. F., and Gordon, J. I. (2004). The gut microbiota as an environmental factor that regulates fat storage. Proc. Natl. Acad. Sci. U.S.A. 101, 15718-15723.

Bäckhed, F., Manchester, J. K., Semenkovich, C. F., and Gordon, J. I. (2007). Mechanisms underlying the resistance to dietinduced obesity in germ-free mice. Proc. Natl. Acad. Sci. U.S.A. 104, 979-984.

Bailey, M. T., and Coe, C. L. (1999). Maternal separation disrupts the integrity of the intestinal microflora in infant rhesus monkeys. Dev. Psychobiol. 35, 146-155.

Bailey, M. T., Engler, H., and Sheridan, J. F. (2006). Stress induces the translocation of cutaneous and gastrointestinal microflora to secondary lymphoid organs of C57BL/6 mice. J. Neuroimmunol. 171, 29-37.

Bailey, M. T., Lubach, G. R., and Coe, C. L. (2004). Prenatal stress alters bacterial colonization of the gut in infant monkeys. J. Pediatr. Gastroenterol. Nutr. 38, 414-421.

Barbara, G., Stanghellini, V., De Giorgio, R., Cremon, C., Cottrell, G. S.,
Santini, D., Pasquinelli, G., MorselliLabate, A. M., Grady, E. F., Bunnett, N. W., Collins, S. M., and Corinaldesi, R. (2004). Activated mast cells in proximity to colonic nerves correlate with abdominal pain in irritable bowel syndrome. Gastroenterology 126, 693-702.

Beaver, M. H., and Wostmann, B. (1962). Histamine and 5hydroxytryptamine in the intestinal tract of germ-free animals, animals harbouring one microbial species and conventional animals. $\mathrm{Br}$. J. Pharmacol. Chemother. 19, 385.

Bennet, R., Eriksson, M., and Nord, C. E. (2002). The fecal microflora of 1-3month-old infants during treatment with eight oral antibiotics. Infection 30, 158-160.

Bercik, P., Denou, E., Collins, J., Jackson, W., Lu, J., Jury, J., Deng, Y., Blennerhassett, P., Macri, J., Mccoy, K. D., Verdu, E. F., and Collins, S. M. (2011). The intestinal microbiota affect central levels of brain-derived neurotropic factor and behavior in mice. Gastroenterology 141, 599-609.

Berg, R. D. (1996). The indigenous gastrointestinal microflora. Trends Microbiol. 4, 430-435.

Bischoff, S. C. (2010). 'Gut health': a new objective in medicine? BMC Med. 9, 24. doi:10.1186/1741-7015-9-24

Bloom, S. M., Bijanki, V. N., Nava, G. M., Sun, L., Malvin, N. P., Donermeyer, D. L., Dunne, W. M. Jr., Allen, P. M., and Stappenbeck, T. S. (2011). Commensal Bacteroides species induce colitis in host-genotype-specific fashion in a mouse model of inflammatory bowel disease. Cell Host Microbe 9, 390-403.

Bloom, S. R., Kuhajda, F. P., Laher, I., Pi-Sunyer, X., Ronnett, G. V., Tan, T. M. M., and Weigle, D. S. (2008). The obesity epidemic pharmacological challenges. Mol. Interv. 8, 82-98.

Blumberg, R. S., and Strober, W. (2001). Prospects for research in inflammatory bowel disease. J. Am. Med. Assoc. 285, 643-647.

Bolte, E. R. (1998). Autism and Clostridium tetani. Med. Hypotheses 51, 133-144.

Bravo, J. A., Forsythe, P., Chew, M. V., Escaravage, E., Savignac, H. M., Dinan, T. G., Bienenstock, J., and Cryan, J. F. (2011). Ingestion of Lactobacillus strain regulates emotional behavior and central GABA receptor expression in a mouse via the vagus nerve. Proc. Natl. Acad. Sci. doi: 10.1073/pnas.1102999108

Brenner, D. M., Moeller, M. J., Chey, W. D., and Schoenfeld, P. S. (2009). The utility of probiotics in the treatment of irritable bowel syndrome: a systematic review. Am. J. Gastroenterol. 104, 1033-1049; quiz 1050.

Brint, E. K., Macsharry, J., Fanning, A., Shanahan, F., and Quigley, E. M. M. (2011). Differential expression of toll-like receptors in patients with irritable bowel syndrome. Am. J. Gastroenterol. 106, 329-336.

Camilleri, M. (2001). Management of the irritable bowel syndrome. Gastroenterology 120, 652-668.

Cario, E., Gerken, G., and Podolsky, D. K. (2004). Toll-like receptor 2 enhances ZO-1-associated intestinal epithelial barrier integrity via protein kinase C. Gastroenterology 127, 224-238.

Cash, H. L., Whitham, C. V., Behrendt, C. L., and Hooper, L. V. (2006). Symbiotic bacteria direct expression of an intestinal bactericidal lectin. Science 313, 1126-1130.

Cenac, N., Andrews, C. N., Holzhausen, M., Chapman, K., Cottrell, G., Andrade-Gordon, P., Steinhoff, M., Barbara, G., Beck, P., Bunnett, N. W., Sharkey, K. A., Ferraz, J. G. P., Shaffer, E., and Vergnolle, N. (2007). Role for protease activity in visceral pain in irritable bowel syndrome. J. Clin. Invest. 117, 636-647.

Chadwick, V. S., Chen, W., Shu, D., Paulus, B., Bethwaite, P., Tie, A., and Wilson, I. (2002). Activation of the mucosal immune system in irritable bowel syndrome. Gastroenterology 122, 1778-1783.

Claesson, M. J., Cusack, S., O'Sullivan, O., Greene-Diniz, R., De Weerd, H., Flannery, E., Marchesi, J. R., Falush, D., Dinan, T., Fitzgerald, G., Stanton, C., Van Sinderen, D., O'Connor, M., Harnedy, N., O'Connor, K., Henry, C., O’Mahony, D., Fitzgerald, A. P., Shanahan, F., Twomey, C., Hill, C., Ross, R. P., and O'Toole, P. W. (2011). Composition, variability, and temporal stability of the intestinal microbiota of the elderly. Proc. Natl. Acad. Sci. U.S.A. 108(Suppl. 1), 4586-4591.

Clarke, G., Fitzgerald, P., Hennessy, A. A., Cassidy, E. M., Quigley, E. M., Ross, P., Stanton, C., Cryan, J. F., and Dinan, T. G. (2010). Marked elevations in pro-inflammatory polyunsaturated fatty acid metabolites in females with irritable bowel syndrome. J. Lipid Res. 51, 1186-1192.

Clarke, G., O’Mahony, S. M., Hennessy, A. A., Ross, P., Stanton, C., Cryan, J. F., and Dinan, T. G. (2009a). Chain reactions: early-life stress alters the metabolic profile of plasma polyunsaturated fatty acids in adulthood. Behav. Brain Res. 205, 319-321.
Clarke, G., Quigley, E. M., Cryan, J. F., and Dinan, T. G. (2009b). Irritable bowel syndrome: towards biomarker identification. Trends. Mol. Med. 15, 478-489.

Clayton, E. M., Rea, M. C., Shanahan, F., Quigley, E. M., Kiely, B., Hill, C., and Ross, R. P. (2009). The vexed relationship between Clostridium difficile and inflammatory bowel disease: an assessment of carriage in an outpatient setting among patients in remission. Am. J. Gastroenterol. 104, 1162-1169.

Codling, C., O'Mahony, L., Shanahan, F., Quigley, E., and Marchesi, J. (2010). A molecular analysis of fecal and mucosal bacterial communities in irritable bowel syndrome. Dig. Dis. Sci. 55, 392-397.

Collins, S. M. (2002). A case for an immunological basis for irritable bowel syndrome. Gastroenterology 122, 2078-2080.

Collins, S. M., Denou, E., Verdu, E. F., and Bercik, P. (2009). The putative role of the intestinal microbiota in the irritable bowel syndrome. Dig. Liver Dis. 41, 850-853.

Corr, S. C., Gahan, C. G. M., and Hill, C. (2007a). Impact of selected Lactobacillus and Bifidobacterium species on Listeria monocytogenes infection and the mucosal immune response. FEMS Immunol. Med. Microbiol. 50, 380-388.

Corr, S. C., Li, Y., Riedel, C. U., O’Toole, P. W., Hill, C., and Gahan, C. G. M. (2007b). Bacteriocin production as a mechanism for the antiinfective activity of Lactobacillus salivar ius UCC118. Proc. Natl. Acad. Sci. U.S.A. 104, 7617-7621.

Cryan, J. F., and O'Mahony, S. M. (2011). The microbiome-gut-brain axis: from bowel to behavior. $\mathrm{Neu}$ rogastroenterol. Motil. 23, 187-192.

Demaude, J., Salvador-Cartier, C., Fioramonti, J., Ferrier, L., and Bueno, L. (2006). Phenotypic changes in colonocytes following acute stress or activation of mast cells in mice: implications for delayed epithelial barrier dysfunction. Gut 55, 655-661.

Desbonnet, L., Garrett, L., Clarke, G., Bienenstock, J., and Dinan, T. G. (2008). The probiotic Bifidobacteria infantis: an assessment of potential antidepressant properties in the rat. J. Psychiatr. Res. 43, 164-174.

Desbonnet, L., Garrett, L., Clarke, G., Kiely, B., Cryan, J. F., and Dinan, T. G. (2010). Effects of the probiotic Bifidobacterium infan$t i s$ in the maternal separation model of depression. Neuroscience 170, 1179-1188. 
Dinan, T. G., Clarke, G., Quigley, E. M., Scott, L. V., Shanahan, F., Cryan, J., Cooney, J., and Keeling, P. W. (2008). Enhanced cholinergic-mediated increase in the pro-inflammatory cytokine IL-6 in irritable bowel syndrome: role of muscarinic receptors. Am. J. Gastroenterol. 103, 2570-2576.

Dinan, T. G., Quigley, E. M., Ahmed, S. M., Scully, P., O’Brien, S., O'Mahony, L., O'Mahony, S., Shanahan, F., and Keeling, P. W. (2006). Hypothalamicpituitary-gut axis dysregulation in irritable bowel syndrome: plasma cytokines as a potential biomarker? Gastroenterology 130, 304-311.

Donskey, C. J., Hujer, A. M., Das, S. M., Pultz, N. J., Bonomo, R. A., and Rice, L. B. (2003). Use of denaturing gradient gel electrophoresis for analysis of the stool microbiota of hospitalized patients. J. Microbiol. Methods 54, 249-256.

Drossman, D. A., Camilleri, M., Mayer, E. A., and Whitehead, W. E. (2002). AGA technical review on irritable bowel syndrome. Gastroenterology 123, 2108-2131.

Dunlop, S. P., Jenkins, D., Neal, K. R., and Spiller, R. C. (2003). Relative importance of enterochromaffin cell hyperplasia, anxiety, and depression in postinfectious IBS. Gastroenterology 125, 1651-1659.

Eckburg, P. B., Bik, E. M., Bernstein, C. N., Purdom, E., Dethlefsen, L., Sargent, M., Gill, S. R., Nelson, K. E., and Relman, D. A. (2005). Diversity of the human intestinal microbial flora. Science 308, 1635-1638.

Ewaschuk, J. B., Diaz, H., Meddings, L., Diederichs, B., Dmytrash, A., Backer, J., Looijer-Van Langen, M., and Madsen, K. L. (2008). Secreted bioactive factors from Bifidobacterium infantis enhance epithelial cell barrier function. Am. J. Physiol. Gastrointest. Liver Physiol. 295, G1025-G1034.

Finegold, S. M. (2008). Therapy and epidemiology of autism-clostridial spores as key elements. Med. Hypotheses 70, 508-511.

Finegold, S. M., Dowd, S. E., Gontcharova, V., Liu, C., Henley, K. E., Wolcott, R. D., Youn, E., Summanen, P. H., Granpeesheh, D., Dixon, D., Liu, M., Molitoris, D. R., and Green Iii, J. A. (2010). Pyrosequencing study of fecal microflora of autistic and control children. Anaerobe 16, 444-453.

Finegold, S. M., Molitoris, D., Song, Y., Liu, C., Vaisanen, M. L., Bolte, E., Mcteague, M., Sandler, R., Wexler,
H., and Marlowe, E. M. (2002). Gastrointestinal microflora studies in late-onset autism. Clin. Infect. Dis. 35, S6.

Forsythe, P., Sudo, N., Dinan, T., Taylor, V. H., and Bienenstock, J. (2010). Mood and gut feelings. Brain Behav. Immun. 24, 9-16.

Frank, D. N., St Amand, A. L., Feldman, R. A., Boedeker, E. C., Harpaz, N., and Pace, N. R. (2007). Molecular-phylogenetic characterization of microbial community imbalances in human inflammatory bowel diseases. Proc. Natl. Acad. Sci. U.S.A. 104, 13780-13785.

Freestone, P. P., Williams, P. H., Haigh, R. D., Maggs, A. F., Neal, C. P., and Lyte, M. (2002). Growth stimulation of intestinal commensal Escherichia coli by catecholamines: a possible contributory factor in traumainduced sepsis. Shock 18, 465-470.

Freestone, P. P. E., Haigh, R. D., Williams, P. H., and Lyte, M. (2003). Involvement of enterobactin in norepinephrine-mediated iron supply from transferrin to enterohaemorrhagic Escherichia coli. FEMS Microbiol. Lett. 222, 39-43.

Gareau, M. G., Wine, E., Rodrigues, D. M., Cho, J. H., Whary, M. T., Philpott, D. J., Macqueen, G., and Sherman, P. M. (2011). Bacterial infection causes stress-induced memory dysfunction in mice. Gut 60, 307-317.

Gill, S. R., Pop, M., Deboy, R. T., Eckburg, P. B., Turnbaugh, P. J., Samuel, B. S., Gordon, J. I., Relman, D. A., Fraser-Liggett, C. M., and Nelson, K. E. (2006). Metagenomic analysis of the human distal gut microbiome. Science 312, 1355-1359.

Glaister, J. (1973). Factors affecting the lymphoid cells in the small intestinal epithelium of the mouse. Int. Arch. Allergy Immunol. 45, 719-730.

Gordon, H. A. (1959). Morphological and physiological characterization of germfree life. Ann. N. Y. Acad. Sci. 78, 208-220.

Gordon, H. A., and Bruckner-Kardoss, E. (1961). Effect of normal microbial flora on intestinal surface area. Am. J. Physiol. 201, 175.

Greer, J. B., and O'Keefe, S. J. (2011). Microbial induction of immunity, inflammation, and cancer. Front. Physiol. 1:168. doi:10.3389/fphys.2010.00168

Guarner, F., Ellen Sanders, M., Gibson, G., Klaenhammer, T., Cabana, M., Scott, K., Reid, G., Delzenne, N. M., Fahey, G. C., and Hill, C. (2011). Probiotic and prebiotic claims in Europe: seeking a clear roadmap. $\mathrm{Br}$. J. Nutr. 1, 1-3.
Gwee, K., Collins, S., Read, N., Rajnakova, A., Deng, Y., Graham, J., Mckendrick, M., and Moochhala, S. (2003). Increased rectal mucosal expression of interleukin 1 in recently acquired post-infectious irritable bowel syndrome. Gut 52, 523.

Gwee, K., Leong, Y., Graham, C., Mckendrick, M., Collins, S., Walters, S., Underwood, J., and Read, N. (1999). The role of psychological and biological factors in postinfective gut dysfunction. Gut 44, 400.

Haslam, D. W., and James, W. P. T. (2005). Obesity. Lancet 366, 1197-1209.

Heijtz, R. D., Wang, S., Anuar, F., Qian, Y., Bjorkholm, B., Samuelsson, A., Hibberd, M. L., Forssberg, H., and Pettersson, S. (2011). Normal gut microbiota modulates brain development and behavior. Proc. Natl. Acad. Sci. U.S.A. 108, 3047-3052.

Heuvelin, E., Lebreton, C., Bichara, M., Cerf-Bensussan, N., and Heyman, M. (2009). A Bifidobacterium probiotic strain and its soluble factors alleviate chloride secretion by human intestinal epithelial cells. J. Nutr. 140 , 7-11.

Hong, K. S., Kang, H. W., Im, J. P., Ji, G. E., Kim, S. G., Jung, H. C., Song, I. S., and Kim, J. S. (2009). Effect of probiotics on symptoms in Korean adults with irritable bowel syndrome. Gut Liver 3, 101-107.

Hong, Y. S., Hong, K. S., Park, M. H., Ahn, Y. T., Lee, J. H., Huh, C. S., Lee, J., Kim, I. K., Hwang, G. S., and Kim, J. S. (2011). Metabonomic understanding of probiotic effects in humans with irritable bowel syndrome. J. Clin. Gastroenterol. 45, 415-425.

Hooper, L. V., Stappenbeck, T. S., Hong, C. V., and Gordon, J. I. (2003). Angiogenins: a new class of microbicidal proteins involved in innate immunity. Nat. Immunol. 4, 269-273.

Hooper, L. V., Wong, M. H., Thelin, A., Hansson, L., Falk, P. G., and Gordon, J. I. (2001). Molecular analysis of commensal host-microbial relationships in the intestine. Science 291, 881-884.

Joossens, M., Huys, G., Cnockaert, M. De Preter, V., Verbeke, K., Rutgeerts, P., Vandamme, P., and Vermeire, S. (2011). Dysbiosis of the faecal microbiota in patients with Crohn's disease and their unaffected relatives. Gut 60, 631-637.

Kajander, K., Hatakka, K., Poussa, T., Farkkila, M., and Korpela, R. (2005). A probiotic mixture alleviates symptoms in irritable bowel syndrome patients: a controlled 6-month intervention. Aliment. Pharmacol. Ther. 22, 387-394.

Kajander, K., Myllyluoma, E., RajilicStojanovic, M., Kyronpalo, S., Rasmussen, M., Jarvenpaa, S., Zoetendal, E. G., De Vos, W. M., Vapaatalo, H., and Korpela, R. (2008). Clinical trial: multispecies probiotic supplementation alleviates the symptoms of irritable bowel syndrome and stabilizes intestinal microbiota. Aliment. Pharmacol. Ther. 27, 48-57.

Kassinen, A., Krogius-Kurikka, L., Mäkivuokko, H., Rinttilä, T., Paulin, L., Corander, J., Malinen, E., Apajalahti, J., and Palva, A. (2007). The fecal microbiota of irritable bowel syndrome patients differs significantly from that of healthy subjects. Gastroenterology 133, 24-33.

Kerckhoffs, A. P. M., Samsom, M., Van Der Rest, M. E., De Vogel, J., Knol, J., Ben-Amor, K., and Akkermans, L. M. A. (2009). Lower Bifidobacteria counts in both duodenal mucosaassociated and fecal microbiota in irritable bowel syndrome patients. World J. Gastroenterol. 15, 2887.

Kiliaan, A. J., Saunders, P. R., Bijlsma, P. B., Berin, M. C., Taminiau, J. A., Groot, J. A., and Perdue, M. H. (1998). Stress stimulates transepithelial macromolecular uptake in rat jejunum. Am. J. Physiol. 275, G1037-G1044.

Kopp-Hoolihan, L. (2001). Prophylactic and therapeutic uses of probiotics: a review. J. Am. Diet. Assoc. 101, 229-238; quiz 239-241.

Kurokawa, K., Itoh, T., Kuwahara, T., Oshima, K., Toh, H., Toyoda, A., Takami, H., Morita, H., Sharma, V. K., and Srivastava, T. P. (2007). Comparative metagenomics revealed commonly enriched gene sets in human gut microbiomes. DNA Res. 14, 169.

Ley, R. E., Bäckhed, F., Turnbaugh, P., Lozupone, C. A., Knight, R. D., and Gordon, J. I. (2005). Obesity alters gut microbial ecology. Proc. Natl. Acad. Sci. U.S.A. 102, 11070-11075.

Ley, R. E., Peterson, D. A., and Gordon, J. I. (2006a). Ecological and evolutionary forces shaping microbial diversity in the human intestine. Cell 124, 837-848.

Ley, R. E., Turnbaugh, P. J., Klein, S., and Gordon, J. I. (2006b). Microbial ecology: human gut microbes associated with obesity. Nature 444, 1022-1023.

Lichtenstein, G. R. (2000). Chemokines and cytokines in inflammatory bowel disease and their application to disease treatment. Curr. Opin. Gastroenterol. 16, 83-88. 
Liebregts, T., Adam, B., Bredack, C., Röth, A., Heinzel, S., Lester, S., Downie-Doyle, S., Smith, E., Drew, P., Talley, N. J., and Holtmann, G. (2007). Immune activation in patients with irritable bowel syndrome. Gastroenterology 132, 913-920.

Lupp, C., Robertson, M. L., Wickham, M. E., Sekirov, I., Champion, O. L., Gaynor, E. C., and Finlay, B. B. (2007). Host-mediated inflammation disrupts the intestinal microbiota and promotes the overgrowth of Enterobacteriaceae. Cell Host Microbe 2, 204.

Lyra, A., Krogius-Kurikka, L., Nikkila, J., Malinen, E., Kajander, K., Kurikka, K., Korpela, R., and Palva, A. (2010). Effect of a multispecies probiotic supplement on quantity of irritable bowel syndromerelated intestinal microbial phylotypes. BMC Gastroenterol. 10, 110. doi:10.1186/1471-230X-10-110

Lyte, M., Li, W., Opitz, N., Gaykema, R., and Goehler, L. E. (2006). Induction of anxiety-like behavior in mice during the initial stages of infection with the agent of murine colonic hyperplasia Citrobacter rodentium. Physiol. Behav. 89, 350-357.

MacDonald, T. T., and Monteleone, G. (2005). Immunity, inflammation, and allergy in the gut. Science 307, 1920.

Macfarlane, G., Blackett, K., Nakayama, T., Steed, H., and Macfarlane, S. (2009). The gut microbiota in inflammatory bowel disease. Curr. Pharm. Des. 15, 1528-1536.

Macfarlane, S., and Macfarlane, G. T. (2003). Regulation of short-chain fatty acid production. Proc. Nutrition Soc. 62, 67-72.

Mackie, R. I., Sghir, A., and Gaskins, H. R. (1999). Developmental microbial ecology of the neonatal gastrointestinal tract. Am. J. Clin. Nutr. 69, 1035S-1045S.

Malinen, E., Rinttila, T., Kajander, K., Matto, J., Kassinen, A., Krogius, L., Saarela, M., Korpela, R., and Palva, A. (2005). Analysis of the fecal microbiota of irritable bowel syndrome patients and healthy controls with real-time PCR. Am. J. Gastroenterol. 100, 373-382.

Mändar, R., and Mikelsaar, M. (1996). Transmission of mother's microflora to the newborn at birth. Neonatology $69,30-35$.

Mangell, P., Nejdfors, P., Wang, M., Ahrne, S., Westrom, B., Thorlacius, H., and Jeppsson, B. (2002). Lactobacillus plantarum $299 \mathrm{v}$ inhibits Escherichia coli-induced intestinal permeability. Dig. Dis. Sci. 47, 511-516.
Marshall, J. K., Thabane, M., Borgaonkar, M. R., and James, C. (2007). Postinfectious irritable bowel syndrome after a food-borne outbreak of acute gastroenteritis attributed to a viral pathogen. Clin. Gastroenterol. Hepatol. 5, 457-460.

Marshall, J. K., Thabane, M., Garg, A. X., Clark, W. F., Salvadori, M., and Collins, S. M. (2006). Incidence and epidemiology of irritable bowel syndrome after a large waterborne outbreak of bacterial dysentery. Gastroenterology 131, 445-450.

Marteau, P. (2010). Probiotics in functional intestinal disorders and IBS: proof of action and dissecting the multiple mechanisms. Gut 59, 285-286.

Matsumoto, S., Setoyama, H., and Umesaki, Y. (1992). Differential induction of major histocompatibility complex molecules on mouse intestine by bacterial colonization. Gastroenterology 103, 1777.

Mättö, J., Maunuksela, L., Kajander, K., Palva, A., Korpela, R., Kassinen, A., and Saarela, M. (2005). Composition and temporal stability of gastrointestinal microbiota in irritable bowel syndrome - a longitudinal study in IBS and control subjects. FEMS Immunol. Med. Microbiol. 43, 213-222.

Mawdsley, J. E., and Rampton, D. S. (2006). The role of psychological stress in inflammatory bowel disease. Neuroimmunomodulation 13, 327-336.

Mayer, E. A. (2011). Gut feelings: the emerging biology of gut-brain communication. Nat. Rev. Neurosci. 12, 453-466.

Mayer, L. (2003). Mucosal immunity. Pediatrics 111, 1595-1600.

Mazmanian, S. K., Liu, C. H., Tzianabos, A. O., and Kasper, D. L. (2005). An immunomodulatory molecule of symbiotic bacteria directs maturation of the host immune system. Cell $122,107-118$.

McCracken, V. J., and Lorenz, R. G. (2001). The gastrointestinal ecosystem: a precarious alliance among epithelium, immunity and microbiota. Cell. Microbiol. 3, 1-11.

McKernan, D. P., Fitzgerald, P., Dinan, T. G., and Cryan, J. F. (2010). The probiotic Bifidobacterium infantis 35624 displays visceral antinociceptive effects in the rat. Neurogastroenterol. Motil. 22, 1029-1035, e1268.

McKernan, D. P., Gaszner, G., Quigley, E. M., Cryan, J. F., and Dinan, T. G. (2011). Altered peripheral toll-like receptor responses in the irritable bowel syndrome. Aliment. Pharmacol. Ther. 33, 1045-1052.
Melgar, S., and Shanahan, F. (2010). Inflammatory bowel disease-from mechanisms to treatment strategies. Autoimmunity 43, 463-477.

Messaoudi, M., Lalonde, R., Violle, N., Javelot, H., Desor, D., Nejdi, A., Bisson, J. F., Rougeot, C., Pichelin, M., Cazaubiel, M., and Cazaubiel, J. M. (2011). Assessment of psychotropic-like properties of a probiotic formulation (Lactobacillus helveticus R0052 and Bifidobacterium longum R0175) in rats and human subjects. Br. J. Nutr. 105 755-764.

Mikkelsen, H. B., Garbarsch, C., Tranum-Jensen, J., and Thuneberg, L. (2004). Macrophages in the small intestinal muscularis externa of embryos, newborn and adult germfree mice. J. Mol. Histol. 35, 377-387.

Million, M., Maraninchi, M., Henry, M., Armougom, F., Richet, H., Carrieri, P., Valero, R., Raccah, D. Vialettes, B., and Raoult, D. (2011). Obesity-associated gut microbiota is enriched in Lactobacillus reuter and depleted in Bifidobacterium animalis and Methanobrevibacter smithii. Int. J. Obes. (Lond.). doi 10.1038/ijo.2011.153

Moayyedi, P., Ford, A. C., Talley, N. J., Cremonini, F., Foxx-Orenstein, A. E., Brandt, L. J., and Quigley, E. M. (2008). The efficacy of probiotics in the treatment of irritable bowel syndrome: a systematic review. Gut 59 , 325-332.

Moreau, M. C., Ducluzeau, R., GuyGrand, D., and Muller, M. C. (1978). Increase in the population of duodenal immunoglobulin a plasmocytes in axenic mice associated with different living or dead bacterial strains of intestinal origin. Infect. Immun. 21, 532-539.

Neufeld, K. M., Kang, N., Bienenstock, J., and Foster, J. A. (2011). Reduced anxiety-like behavior and central neurochemical change in germ-free mice. Neurogastroenterol. Motil. 23, 255-264.

O'Hara, A. M., and Shanahan, F. (2006). The gut flora as a forgotten organ. EMBO Rep. 7, 688-693.

O'Mahony, L., Mccarthy, J., Kelly, P., Hurley, G., Luo, F., Chen, K., O'Sullivan, G. C., Kiely, B., Collins, J. K., Shanahan, F., and Quigley, E. M. (2005). Lactobacillus and Bifidobacterium in irritable bowel syndrome: symptom responses and relationship to cytokine profiles. Gastroenterology 128, 541-551.

O'Mahony, S. M., Hyland, N. P., Dinan, T. G., and Cryan, J. F. (2011). Maternal separation as a model of braingut axis dysfunction. Psychopharmacology (Berl.) 214, 71-88.
O'Mahony, S. M., Marchesi, J. R., Scully, P., Codling, C., Ceolho, A. M., Quigley, E. M., Cryan, J. F., and Dinan, T. G. (2009). Early life stress alters behavior, immunity, and microbiota in rats: implications for irritable bowel syndrome and psychiatric illnesses. Biol. Psychiatry 65, 263-267.

Palmer, C., Bik, E. M., Digiulio, D. B., Relman, D. A., and Brown, P. O. (2007). Development of the human infant intestinal microbiota. PLoS Biol. 5, e177. doi:10.1371/journal.pbio.0050177

Pandol, S. J. (2010). Integrating the gastrointestinal sciences. Front. Physiol. 1:19. doi:10.3389/fphys.2010.00019

Parracho, H. M., Bingham, M. O., Gibson, G. R., and Mccartney, A. L. (2005). Differences between the gut microflora of children with autistic spectrum disorders and that of healthy children. J. Med. Microbiol. 54, 987-991.

Parvez, S., Malik, K. A., Ah Kang, S., and Kim, H. Y. (2006). Probiotics and their fermented food products are beneficial for health. J. Appl. Microbiol. 100, 1171-1185.

Podolsky, D. K. (2002). Inflammatory bowel disease. N. Engl. J. Med. 347, 417-429.

Qin, J., Li, R., Raes, J., Arumugam, M., Burgdorf, K. S., Manichanh, C., Nielsen, T., Pons, N., Levenez, F., Yamada, T., Mende, D. R., Li, J., Xu, J., Li, S., Li, D., Cao, J., Wang, B. Liang, H., Zheng, H., Xie, Y., Tap, J., Lepage, P., Bertalan, M., Batto, J.M., Hansen, T., Le Paslier, D., Linneberg, A., Nielsen, H. B., Pelletier, E., Renault, P., Sicheritz-Ponten, T., Turner, K., Zhu, H., Yu, C., Li, S., Jian, M., Zhou, Y., Li, Y., Zhang, X., Li, S., Qin, N., Yang, H., Wang, J., Brunak, S., Dore, J., Guarner, F., Kristiansen, K., Pedersen, O., Parkhill, J., Weissenbach, J., Bork, P., Ehrlich, S. D., and Wang, J. (2010). A human gut microbial gene catalogue established by metagenomic sequencing. Nature 464, 59-65.

Quigley, E. M. (2007). Bacterial flora in irritable bowel syndrome: role in pathophysiology, implications for management. J. Dig. Dis. 8, 2-7.

Quigley, E. M. (2008). Probiotics in functional gastrointestinal disorders: what are the facts? Curr. Opin. Pharmacol. 8, 704-708.

Quigley, E. M. (2009). Do patients with functional gastrointestinal disorders have an altered gut flora? Therap. Adv. Gastroenterol. 2, 23-30.

Quigley, E. M. M. (2011). Antibiotics in irritable bowel syndrome: a novel approach to a challenging disorder. Clin. Investig. (Lond.) 1, 479-482. 
Rajilić-Stojanović, M., Biagi, E., Heilig, H. G. H. J., Kajander, K., Kekkonen, R. A., Tims, S., and De Vos, W. M. (2011). Global and deep molecular analysis of microbiota signatures in fecal samples from patients with irritable bowel syndrome. Gastroenterology 141, 1792-1801.

Rakoff-Nahoum, S., Paglino, J., EslamiVarzaneh, F., Edberg, S., and Medzhitov, R. (2004). Recognition of commensal microflora by toll-like receptors is required for intestinal homeostasis. Cell 118, 229-241.

Reber, S. O. (2011). Stress and animal models of inflammatory bowel disease - An update on the role of the hypothalamo-pituitary-adrenal axis. Psychoneuroendocrinology. doi: 10.1016/j.psyneuen.2011.05.014

Rhee, S. H., Pothoulakis, C., and Mayer, E. A. (2009). Principles and clinical implications of the brain-gutenteric microbiota axis. Nat. Rev. Gastroenterol. Hepatol. 6, 306-314.

Rodríguez, L. A. G., and Ruigómez, A. (1999). Increased risk of irritable bowel syndrome after bacterial gastroenteritis: cohort study. BMJ 318, 565.

Rousseaux, C., Thuru, X., Gelot, A., Barnich, N., Neut, C., Dubuquoy, L., Dubuquoy, C., Merour, E., Geboes, K., Chamaillard, M., Ouwehand, A., Leyer, G., Carcano, D., Colombel, J. F., Ardid, D., and Desreumaux, P. (2007). Lactobacillus acidophilus modulates intestinal pain and induces opioid and cannabinoid receptors. Nat. Med. 13, 35-37.

Ruddick, J. P., Evans, A. K., Nutt, D. J., Lightman, S. L., Rook, G. A., and Lowry, C. A. (2006). Tryptophan metabolism in the central nervous system: medical implications. Expert Rev. Mol. Med. 8, 1-27.

Samuel, B. S., Shaito, A., Motoike, T., Rey, F. E., Backhed, F., Manchester, J. K., Hammer, R. E., Williams, S. C., Crowley, J., Yanagisawa, M., and Gordon, J. I. (2008). Effects of the gut microbiota on host adiposity are modulated by the shortchain fatty-acid binding $G$ proteincoupled receptor, Gpr41. Proc. Natl. Acad. Sci. U.S.A. 105, 16767-16772.

Sandler, R. H., Finegold, S. M., Bolte, E. R., Buchanan, C. P., Maxwell, A. P., Väisänen, M.-L., Nelson, M. N., and Wexler, H. M. (2000). Short-term benefit from oral vancomycin treatment of regressive-onset autism. J. Child Neurol. 15, 429-435.

Sarna, S. K. (2011). Lessons learnt from post-infectious IBS. Front. Physiol. 2:49. doi:10.3389/fphys.2011.00049

Scanlan, P. D., Shanahan, F., O'Mahony, C., and Marchesi, J. R. (2006).
Culture-independent analyses of temporal variation of the dominant fecal microbiota and targeted bacterial subgroups in Crohn's disease. J. Clin. Microbiol. 44, 3980-3988.

Schellekens, H., Dinan, T. G., and Cryan, J. F. (2010). Lean mean fat reducing "ghrelin" machine: hypothalamic ghrelin and ghrelin receptors as therapeutic targets in obesity. Neuropharmacology 58, 2-16.

Scully, P., McKernan, D. P., Keohane, J., Groeger, D., Shanahan, F., Dinan, T. G., and Quigley, E. M. (2010). Plasma cytokine profiles in females with irritable bowel syndrome and extra-intestinal comorbidity. Am. J. Gastroenterol. 105, 2235-2243.

Sekirov, I., Russell, S. L., Antunes, L. C. M., and Finlay, B. B. (2010). Gut microbiota in health and disease. Physiol. Rev. 90, 859-904.

Shanahan, F. (2002). The host-microbe interface within the gut. Best Pract. Res. Clin. Gastroenterol. 16, 915-931.

Shanahan, F. (2004). Probiotics in inflammatory bowel disease - therapeutic rationale and role. Adv. Drug Deliv. Rev. 56, 809-818.

Shanahan, F. (2005). Physiological basis for novel drug therapies used to treat the inflammatory bowel diseases I. Pathophysiological basis and prospects for probiotic therapy in inflammatory bowel disease. Am. J. Physiol. Gastrointest. Liver Physiol. 288, G417-G421.

Shanahan, F. (2010a). Gut microbes: from bugs to drugs. Am. J. Gastroenterol. 105, 275-279.

Shanahan, F. (2010b). Probiotics in perspective. Gastroenterology 139, 1808-1812.

Smith, K., Mccoy, K. D., and Macpherson, A. J. (2007). Use of axenic animals in studying the adaptation of mammals to their commensal intestinal microbiota. Semin. Immunol. 19, 59-69.

Sobko, T., Reinders, C., Norin, E., Midtvedt, T., Gustafsson, L. E., and Lundberg, J. O. (2004). Gastrointestinal nitric oxide generation in germ-free and conventional rats. Am. J. Physiol. Gastrointest. Liver Physiol. 287, G993.

Sokol, H., Seksik, P., Rigottier-Gois, L., Lay, C., Lepage, P., Podglajen, I., Marteau, P., and Doré, J. (2006). Specificities of the fecal microbiota in inflammatory bowel disease. Inflamm. Bowel Dis. 12, 106-111.

Song, Y., Liu, C., and Finegold, S. M. (2004). Real-time PCR quantitation of clostridia in feces of autistic children. Appl. Environ. Microbiol. 70, 6459-6465.
Spiller, R., and Garsed, K. (2009). Postinfectious irritable bowel syndrome. Gastroenterology 136, 1979-1988.

Spiller, R. C., Jenkins, D., Thornley, J. P., Hebden, J. M., Wright, T., Skinner, M., and Neal, K. R. (2000). Increased rectal mucosal enteroendocrine cells, $\mathrm{T}$ lymphocytes, and increased gut permeability following acute Campylobacter enteritis and in post-dysenteric irritable bowel syndrome. Gut 47, 804-811.

Stappenbeck, T. S., Hooper, L. V., and Gordon, J. I. (2002). Developmental regulation of intestinal angiogenesis by indigenous microbes via Paneth cells. Proc. Natl. Acad. Sci. U.S.A. 99, 15451.

Sudo, N., Chida, Y., Aiba, Y., Sonoda, J., Oyama, N., Yu, X. N., Kubo, C., and Koga, Y. (2004). Postnatal microbial colonization programs the hypothalamic-pituitary-adrenal system for stress response in mice. $J$. Physiol. (Lond.) 558, 263-275.

Sumi, Y., Miyakawa, M., Kanzaki, M., and Kotake, Y. (1977). Vitamin B-6 deficiency in germfree rats. J. Nutr. 107, 1707.

Tana, C., Umesaki, Y., Imaoka, A. Handa, T., Kanazawa, M., and Fukudo, S. (2010). Altered profiles of intestinal microbiota and organic acids may be the origin of symptoms in irritable bowel syndrome. $\mathrm{Neu}$ rogastroenterol. Motil. 22, 512-519, e114-e115.

Thompson, W. G., Longstreth, G. F., Drossman, D. A., Heaton, K. W. Irvine, E. J., and Müller-Lissner, S. A. (1999). Functional bowel disorders and functional abdominal pain. Gut 45, II43-II47.

Turnbaugh, P. J., Ley, R. E., Mahowald, M. A., Magrini, V., Mardis, E. R., and Gordon, J. I. (2006). An obesityassociated gut microbiome with increased capacity for energy harvest. Nature 444, 1027-1031.

Ulevitch, R. J. (1999). Endotoxin opens the Tollgates to innate immunity. Nat. Med. 5, 144-145.

Umesaki, Y., Okada, Y., Matsumoto, S., Imaoka, A., and Setoyama, H. (1995). Segmented filamentous bacteria are indigenous intestinal bacteria that activate intraepithelial lymphocytes and induce MHC class II molecules and fucosyl asialo GM1 glycolipids on the small intestinal epithelial cells in the ex-germfree mouse. Microbiol. Immunol. 39, 555-562.

Vaishnava, S., Behrendt, C. L., Ismail, A. S., Eckmann, L., and Hooper, L. V. (2008). Paneth cells directly sense gut commensals and maintain homeostasis at the intestinal host-microbial interface. Proc. Natl. Acad. Sci. U.S.A. 105, 20858-20863.

Verdu, E. F., Bercik, P., Verma-Gandhu, M., Huang, X. X., Blennerhassett, P., Jackson, W., Mao, Y., Wang, L., Rochat, F., and Collins, S. M. (2006). Specific probiotic therapy attenuates antibiotic induced visceral hypersensitivity in mice. Gut 55, 182-190.

Walker, A., Sanderson, J., Churcher, C., Parkes, G., Hudspith, B., Rayment, N., Brostoff, J., Parkhill, J., Dougan, G., and Petrovska, L. (2011). Highthroughput clone library analysis of the mucosa-associated microbiota reveals dysbiosis and differences between inflamed and non-inflamed regions of the intestine in inflammatory bowel disease. BMC Microbiol. 11, 7. doi:10.1186/1471-2180-11-7

Whorwell, P. J. (2009). Do probiotics improve symptoms in patients with irritable bowel syndrome? Therap. Adv. Gastroenterol. 2, 37-44.

Willing, B., Halfvarson, J., Dicksved, J., Rosenquist, M., Järnerot, G., Engstrand, L., Tysk, C., and Jansson, J. K. (2009). Twin studies reveal specific imbalances in the mucosa-associated microbiota of patients with ileal Crohn's disease. Inflamm. Bowel Dis. 15, 653-660.

Woodmansey, E. J. (2007). Intestinal bacteria and ageing. J. Appl. Microbiol. 102, 1178-1186.

Wostmann, B., and Bruckner-Kardoss, E. (1959). Development of cecal distention in germ-free baby rats. Am. J. Physiol. 197, 1345-1346.

Wostmann, B. S. (1981). The germfree animal in nutritional studies. Annu. Rev. Nutr. 1, 257-279.

Wostmann, B. S., Larkin, C., Moriarty, A., and Bruckner-Kardoss, E. (1983). Dietary intake, energy metabolism, and excretory losses of adult male germfree Wistar rats. Lab. Anim. Sci. 33,46 .

Wu, S. V., and Hui, H. (2011). Treat your bug right. Front. Physiol. 2:9. doi:10.3389/fphys.2011.00009

Xu, J., Mahowald, M. A., Ley, R. E., Lozupone, C. A., Hamady, M., Martens, E. C., Henrissat, B., Coutinho, P. M., Minx, P., Latreille, P., Cordum, H., Van Brunt, A., Kim, K., Fulton, R. S., Fulton, L. A., Clifton, S. W., Wilson, R. K., Knight, R. D., and Gordon, J. I. (2007). Evolution of symbiotic bacteria in the distal human intestine. PLoS Biol. 5, e156. doi:10.1371/journal.pbio. 0050156

Zareie, M., Johnson-Henry, K., Jury, J., Yang, P. C., Ngan, B. Y., Mckay, D. M. Soderholm, J. D., Perdue, M. H., and Sherman, P. M. (2006). Probiotics 
prevent bacterial translocation and improve intestinal barrier function in rats following chronic psychological stress. Gut 55, 1553-1560.

Conflict of Interest Statement: The authors declare that the research was conducted in the absence of any commercial or financial relationships that could be construed as a potential conflict of interest.

Received: 15 September 2011; paper pending published: 13 October 2011; accepted: 18 November 2011; published online: 07 December 2011.
Citation: Grenham S, Clarke G, Cryan JF and Dinan TG (2011) Braingut-microbe communication in health and disease. Front. Physio. 2:94. doi: 10.3389/fphys.2011.00094

This article was submitted to Frontiers in Gastrointestinal Sciences, a specialty of Frontiers in Physiology.
Copyright (c) 2011 Grenham, Clarke, Cryan and Dinan. This is an open-acces article distributed under the terms of the Creative Commons Attribution Non Commercial License, which permits noncommercial use, distribution, and reproduction in other forums, provided the original authors and source are credited. 